\title{
Management of Opioid-Induced Constipation and Bowel Dysfunction: Expert Opinion of an Italian Multidisciplinary Panel
}

\author{
Roberto De Giorgio (D) - Furio Massimino Zucco - Giuseppe Chiarioni • \\ Sebastiano Mercadante - Enrico Stefano Corazziari · Augusto Caraceni • \\ Patrizio Odetti · Raffaele Giusti · Franco Marinangeli • \\ Carmine Pinto
}

Received: March 24, 2021 / Accepted: April 28, 2021

(c) The Author(s) 2021

\section{ABSTRACT}

The prescribing and use of opioid analgesics is increasing in Italy owing to a profusion in the number and types of opioid analgesic products available, and the increasing prevalence of

Supplementary Information The online version contains supplementary material available at https:// doi.org/10.1007/s12325-021-01766-y.

R. De Giorgio ( $\square)$

Department of Translational Medicine, University of Ferrara, Via Aldo Moro 8, 44124 Ferrara, Italy e-mail: dgrrrt@unife.it

\section{F. M. Zucco}

School of Specialization in Geriatric Medicine, University of Milan, Milan, Italy

\section{G. Chiarioni}

Division of Gastroenterology of the University of Verona, Azienda Ospedaliera Universitaria Integrata (AOUI) Verona, Verona, Italy

\section{G. Chiarioni}

UNC Center for Functional GI and Motility Disorders, University of North Carolina at Chapel Hill, Chapel Hill, NC, USA

\section{S. Mercadante}

Department of Oncology, La Maddalena, Palermo, Italy

\section{E. S. Corazziari}

Department of Gastroenterology, Clinical Institute Humanitas, Milan, Italy conditions associated with severe pain, the latter being related to population aging. Herein we provide the expert opinion of an Italian multidisciplinary panel on the management of opioid-induced constipation (OIC) and bowel dysfunction. OIC and opioid-induced bowel dysfunction are well-recognised unwanted effects of treatment with opioid analgesics that can profoundly affect quality of life. OIC can be due to additional factors such as reduced mobility, a low-fibre diet, comorbidities, and

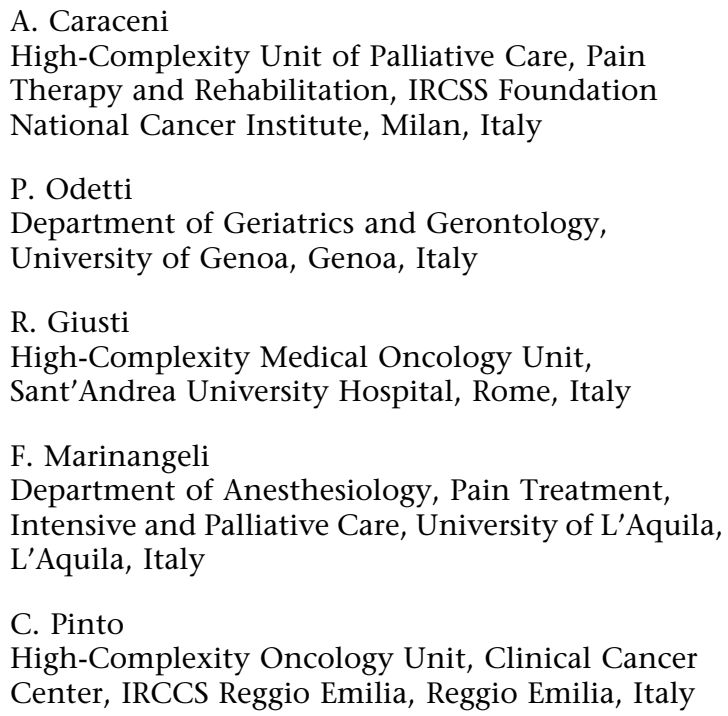


concomitant medications. Fixed-dose combinations of opioids with mu $(\mu)$ opioid receptor antagonists, such as oxycodone/naloxone, have become available, but have limited utility in clinical practice because the individual components cannot be independently titrated, creating a risk of breakthrough pain as the dose is increased. A comprehensive prevention and management strategy for OIC should include interventions that aim to improve fibre and fluid intake, increase mobility or exercise, and restore bowel function without compromising pain control. Recommended first-line pharmacological treatment of OIC is with an osmotic laxative (preferably polyethylene glycol [macrogol]), or a stimulant laxative such as an anthraquinone. A second laxative with a complementary mechanism of action should be added in the event of an inadequate response. Second-line treatment with a peripherally acting $\mu$ opioid receptor antagonist (PAMORA), such as methylnaltrexone, naloxegol or naldemedine, should be considered in patients with OIC that has not responded to combination laxative treatment. Prokinetics or intestinal secretagogues, such as lubiprostone, may be appropriate in the third-line setting, but their use in OIC is off-label in Italy, and should therefore be restricted to settings such as specialist centres and clinical trials.

Keywords: Analgesics; Chronic pain; Functional gastrointestinal disorders; Laxatives; Narcotic antagonists; Opioid; Opioid-induced constipation

\section{Key Summary Points}

Opioids, acting via mu $(\mu)$, delta $(\delta)$ and

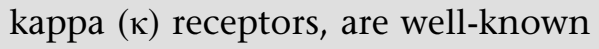
potent analgesic drugs.

Their use in daily clinical practice has significantly increased in Western countries, including Italy, as a result of progressive aging of the general population and an increase in the prevalence of chronic diseases with severe pain.

Although extremely effective, opioids are associated with a number of adverse effects including opioid-induced bowel dysfunction and opioid-induced constipation (OIC). These influence patients' quality of life and cause possible life-threatening complications.

Thus, patients with OIC should be appropriately managed with an integrated strategy based on improving dietary fibre, fluid intake, and exercise, as well as by restoring bowel function without altering the antinociceptive power of opioid drugs.

In line with the international recommendations, our panel indicates the use of either osmotic (i.e. polyethylene glycol) or stimulant laxatives (i.e. anthraquinone) as first-line pharmacological treatment for OIC. Should this approach be inadequate, a second laxative can be added.

For second-line treatment, peripherally acting $\mu$ opioid receptor antagonists (PAMORAs), i.e. methylnaltrexone, naloxegol or naldemedine, are recommended being target therapies for patients with OIC unresponsive to combination of laxatives.

Prokinetics or intestinal secretagogues, i.e. lubiprostone, are off-label for OIC in Italy and their use should be restricted to specialist centres and clinical trials. 


\section{DIGITAL FEATURES}

This article is published with digital features, including a summary slide, to facilitate understanding of the article. To view digital features for this article go to https://doi.org/10.6084/ m9.figshare.14495271.

\section{INTRODUCTION}

Chronic pain is disabling and has a multifactorial aetiology. Many patients require daily medication for pain relief, with opioids playing a central role. In the USA, approximately $4 \%$ of adults are receiving long-term treatment with opioids for the control of chronic, persistent pain, mainly due to causes other than cancer; in 2019, over 153 million prescriptions for opioids were filled [1]. Approximately 15\% of American adults have chronic pain, with prevalence estimates ranging from $2 \%$ to $40 \%$ [2]. A prevalence of $19 \%$ was reported in a survey of 15 European countries, including Italy [3].

In Italy, the use of opioids for chronic pain relief has been steadily increasing since the approval, in 2010, of Law no. 38 (38/2010) [4], which provides access for Italian citizens to national palliative care and pain therapy networks. Despite this, per capita opioid consumption in Italy is still well below average consumption in the USA and elsewhere in Europe $[5,6]$. Table 1 summarises the opioids that are available for clinical use in Italy.

An increase in opioid use is inevitably associated with a concomitant rise in opioid-related adverse events (AEs) [2, 7]. Thus, when initiating or reviewing opioid treatment, particularly in the context of persistent or chronic pain, physicians should consider both benefits and risks, and aim to minimise AEs to avoid treatment discontinuation.

One of the most commonly reported AEs during long-term treatment is opioid-induced constipation (OIC), which is one manifestation of the overall effect of opioids on the gastrointestinal (GI) system (referred to as opioid-induced bowel dysfunction, OIBD) [7]. OIC and
OIBD represent a daily challenge in the care of patients receiving long-term opioid treatment.

In addition to analgesia, opioids are also prescribed to control symptoms and signs related to cardiovascular and respiratory disorders (e.g. dyspnoea), particularly in advanced stages of disease when treatment aimed at correcting the underlying cause is not effective $[8,9]$. Therefore, the need for analgesia may conflict with the potential for AEs that, if not properly controlled, will further compromise quality of life and independence.

\section{METHODS}

More than 10 years after the publication of Italian guidelines on the management of OIC [10], innovations in research have enabled the prescription of new, receptor-selective pharmacological agents for patients with OIC. Consequently, a multidisciplinary panel of 10 experts from across Italy was convened to review the literature on OIC and OIBD, and to formulate treatment recommendations based on both published evidence and expertise gained in different but complementary specialist settings.

The literature review was limited to research papers published in international (English language) and Italian (Italian language) journals between 1 January 2005 and 31 December 2020, identified by searching the MedLine (via PubMed) database and the websites of the Italian Society of Palliative Care or Italian Society of General Medicine and Primary Care. The literature search included both international and Italian studies and was mainly based on the following terms: "analgesics", "cancer pain", "chronic pain", "functional gastrointestinal disorders", "laxatives", "narcotic antagonists", "non-cancer pain", "opioids", "opioid-induced bowel dysfunction", "opioid-induced constipation".

At the end of the first meeting, the expert panel agreed on a schedule and working method for the preparation of the literature synthesis. Panellists were assigned to separate working groups, each of which had responsibility for reviewing a specific topic. Each topic formed the basis of a section of the shared final 
Table 1 Opioids available for the treatment of chronic and persistent pain in Italy in 2021

\begin{tabular}{|c|c|c|}
\hline Active ingredient & Administration route (formulations) & Commercially available fixed-dose combinations \\
\hline \multicolumn{3}{|l|}{ Weak opioids } \\
\hline \multirow[t]{3}{*}{ Codeine } & Oral (tablets, capsules, drops, syrup, granules) & Codeine + paracetamol (acetaminophen) \\
\hline & Rectal & Codeine + aspirin (acetylsalicylic acid) \\
\hline & & Codeine + ibuprofen \\
\hline Dihydrocodeine & Oral (drops, syrup) & Dihydrocodeine + paracetamol \\
\hline \multirow[t]{3}{*}{ Tramadol } & Oral (tablets, drops, vials) & Tramadol + paracetamol \\
\hline & Subcutaneous, intramuscular, intravenous & \\
\hline & Rectal & \\
\hline \multicolumn{3}{|l|}{ Strong opioids } \\
\hline \multirow[t]{3}{*}{ Buprenorphine } & Sublingual (tablets) & Buprenorphine + naloxone \\
\hline & Intramuscular, intravenous & \\
\hline & Transdermal (patch) & \\
\hline \multirow[t]{5}{*}{ Fentanyl } & Sublingual (oral dissolving tablets) & \\
\hline & Transmucosal (lozenges with applicator) & \\
\hline & Intranasal (spray) & \\
\hline & Intravenous & \\
\hline & Transdermal (patch) & \\
\hline Hydromorphone & Oral (tablets) & \\
\hline \multirow[t]{3}{*}{ Methadone } & Oral (solution, syrup) & \\
\hline & Subcutaneous, intramuscular, intravenous & \\
\hline & Rectal & \\
\hline \multirow[t]{3}{*}{ Morphine sulfate } & Oral (tablets, capsules, drops, syrup, ampoules) & \\
\hline & Subcutaneous, intramuscular, intravenous & \\
\hline & Rectal & \\
\hline \multirow[t]{4}{*}{ Oxycodone } & Oral (tablets, capsules) & Oxycodone + paracetamol \\
\hline & & Oxycodone + naloxone \\
\hline & Subcutaneous, intramuscular, intravenous & \\
\hline & Rectal & \\
\hline Sufentanil & Sublingual (tablets) & \\
\hline Tapentadol & Oral (tablets, solution) & \\
\hline
\end{tabular}


document. In order for the panellists to finalise and produce an expert recommendation, there had to be unanimous agreement amongst all panellists.

This article is based on previously conducted studies and does not contain any new studies with human participants or animals performed by any of the authors.

\section{PATHOPHYSIOLOGY}

The opioidergic system has a profound influence on GI physiology. Opioid receptors delta $(\delta)$, kappa (к) and mu ( $\mu$ ) are G-protein-coupled receptors abundantly expressed throughout the GI tract [11-13]. Mapping the distribution of each receptor type in mammals is a highly complex process, as it may vary depending on the intestinal region or layer being considered and on the species under investigation. Experimental studies conducted on guinea pigs and rats showed a high concentration of $\mu$ and $\kappa$ receptors in the stomach and proximal colon [11, 14, 15]. In humans, evidence on the distribution of opioid receptors and their subclasses is limited, but $\mu$ receptors are nonetheless thought to play a central role in GI physiology. Immunohistochemical studies have shown that these receptors are located on the cytoplasmic membrane of submucosal and myenteric neurons in the enteric nervous system, also known as the "brain in the gut'. They have also been found in mononuclear cells in the lamina propria, and in enteroendocrine cells of the mucosa, smooth muscle and interstitial cells of Cajal (ICCs), the latter referred to as the 'pacemaker' cells of the GI tract. Conversely, $\mu$ receptors have not been detected in epithelial cells [11, 13, 14, 16].

A variety of endogenous (encephalins, endorphins and dynorphins) and exogenous (opioids) ligands can bind to opioid receptors, resulting in their internalisation and coupling with inhibitory Gi/Go proteins that activate or inhibit downstream messengers [11, 17]. Collectively, opioid receptors modulate GI function by decreasing neuronal excitability and neurotransmitter release, which translates into an overall inhibitory effect on GI motility and secretion [12].
Unlike their analgesic effects, the adverse GI effects of opioids are not characterised by the development of tolerance. In preclinical studies, tolerance seems to vary between intestinal regions: while no tolerance develops in the colon, the effects of opioids on the small intestine tend to disappear over time [18, 19]. The mechanisms underlying opioid tolerance are unclear but may involve $\mu$ receptor signal transducers (i.e. $\beta$-arrestins) [18-20].

GI motility is controlled by a subtle balance between the neurotransmitters and neuromodulators released by myenteric neurons. More specifically, excitatory motor neurons release acetylcholine and tachykinins (including substance $\mathrm{P}$ ) to elicit longitudinal smooth muscle contraction, whereas inhibitory motor neurons induce smooth muscle relaxation mostly by way of nitric oxide and vasoactive intestinal polypeptide (VIP) [21, 22].

Opioids inhibit the release of neurotransmitters, directly disrupting the normal coordination of GI motility; in turn, this results in increased muscle tone and a marked reduction in propulsive activity $[11,23]$. Opioid $\mu$ receptors are especially involved in this process, as demonstrated by the fact that the inhibitory effects of morphine on GI motility have not been detected in $\mu$ receptor knockout mice [24]. Human studies have shown that the administration of opioids inhibits motility of the oesophagus and gall bladder [11, 21, 25, 26], delays gastric emptying, and prolongs oro-caecal and colonic transit times [11, 27-29]. Using a non-invasive technique, Poulsen and coworkers demonstrated that slow-release orally administered oxycodone reduced colonic transit time, especially in the ascending and rectosigmoid colon [30]. These results were confirmed in colonography studies, which revealed a greater concentration of faeces in the caecum and ascending colon [31]. Because emptying of the colon may be initiated by ICCs (pacemaker cells) in the caecum, disruption of this function may be a major barrier to treatment with conventional laxatives [32]. Naloxone (a centrally acting $\mu$ receptor antagonist) [33] and naloxegol (a peripherally acting $\mu$ receptor antagonist) [34] restored normal colonic motility and transit patterns in opioid-treated 
healthy volunteers, demonstrating the potential of $\mu$ receptor antagonism in reversing the GI effects of opioids.

Opioid receptors also have effects on secretion and absorption in the GI tract [11,35]. Activation of opioid receptors inhibits the release of acetylcholine from neurons innervating the salivary glands, reducing saliva production; this causes dry mouth, a common unwanted effect of opioid treatment. Enterocyte secretion is mainly regulated by submucosal neurons containing several pro-secretory mediators, such as acetylcholine and VIP $[16,17,36]$. Release of these transmitters into the basolateral compartment of the mucous coat $[21,37]$ increases intracellular levels of cyclic adenosine monophosphate and cyclic guanosine monophosphate [38, 39] and this, in turn, activates chloride channels at the epithelial cell level. Chloride secretion into the intestinal lumen draws water across an osmotic gradient $[20,40]$. As with intestinal motility, most of the mechanisms by which opioids regulate human intestinal secretion are mediated by $\mu$ receptors $[17,21]$, stimulation of which blocks acetylcholine and VIP release, resulting in reduced chloride and water secretion [12, 17, 20, 21, 41].

Opioids also reduce biliary and pancreatic secretions, which further disrupts intestinal physiology, impairing digestion and the absorption of nutrients and drugs [42-44]. In addition, prolonged stasis of intestinal content due to inhibition of intestinal motility increases water absorption, altering secretory processes [11]. In the colon, intrinsic neuronal reflexes that trigger propulsive contractions are dependent on the activation of mechanoreceptors, and a reduced faecal volume will therefore reduce motility [11, 41, 42]. Patients treated with opioids often complain of hard, dry faeces that contribute to constipation [11].

Finally, opioid receptor stimulation increases resting muscle tone of, and therefore the pressure exerted by, all six sphincters of the human GI tract $[12,17,45]$. Although a detailed discussion of this effect is beyond the scope of this review, it is important to remember that opioids increase contraction of the internal anal sphincter, which, in turn, contributes to OIC $[11,41]$. Increased sphincter tone during opioid treatment can be significantly decreased with naloxegol [34].

In summary, opioids, primarily through their action on $\mu$ receptors, promote the development of OIC by inhibiting GI motility and secretion, and by increasing sphincter contractility (especially of the internal anal sphincter). These mechanisms provide the rationale for the development of peripheral $\mu$ receptor antagonists as potential treatments for OIC.

\section{DEFINITIONS}

\section{Definition of OIBD}

Because $\mu$ receptors are distributed throughout the GI tract, patients may experience symptoms involving the upper and/or lower GI tract (Table 2), either simultaneously or independently [46]. This complex condition is known as OIBD. The prevalence of OIBD varies between opioids, with morphine showing a higher prevalence of constipation compared with controlled-release oxycodone or transdermally administered buprenorphine [47].

Unlike lower GI tract symptoms, those affecting the upper tract tend to improve spontaneously over time as a result of tolerance, even in the absence of changes in opioid dosage $[36,46]$. The lack of well-defined diagnostic criteria has precluded the performance of clinical therapeutic studies focusing on OIBD, and this has hindered the formulation and adoption of a universal definition of OIBD.

We propose that OIBD should be defined as a constellation of symptoms and signs with GI localisation/origin that either appear or worsen during the course of opioid treatment, and persist for at least 2 weeks. We further propose that, for OIBD to be diagnosed, at least two of the signs and symptoms listed in Table 3 must be present. The rationale for the minimum 2-week symptoms duration is to differentiate OIBD from self-limiting GI conditions (e.g. viral infections) that are unrelated to opioid use.

Finally, OIBD should be clinically distinguished from OIC, a syndrome specifically related to difficulty in passing a bowel movement. 
Table 2 Opioid-induced gastrointestinal symptoms

\begin{tabular}{l} 
Symptoms of the upper gastrointestinal tract \\
\hline Dysphagia \\
Retrosternal pain \\
Heartburn \\
Symptoms related to gastro-oesophageal reflux \\
Epigastric pain \\
Dyspepsia \\
Nausea \\
Vomiting
\end{tabular}

Symptoms of the lower gastrointestinal tract

Bloating

Flatulence

Abdominal pain

Distention

Constipation

Tenesmus

\section{Definition of OIC}

To date, most studies of OIC have been characterised by discrepancies, uncertainty and imprecise clinical descriptions, which means that the available epidemiological data are extremely variable. These shortcomings have prompted efforts to develop a standardised definition of OIC $[11,23,48-51]$.

On the basis of an analysis of 47 studies and 16 definitions, the authors of a recent review [52] emphasised the need to consider change in bowel habits and patterns. They defined OIC as a change in bowel habit that appeared after the initiation of opioid therapy, and was characterised by one of the following: a reduced frequency of bowel movements; development or worsening of straining to pass bowel movements; a sense of incomplete rectal evacuation; or harder stool consistency [52]. Stool consistency and appearance may be determined by using the Bristol Stool Form Scale (BSFS) [53], which classifies stools on a scale from grade 1 (hard lumps) to 6 (watery diarrhoea).

Subsequently, the Rome Foundation produced the so-called Rome IV criteria, which proposed that OIC should be defined as new or worsening constipation when initiating, changing or increasing opioid therapy, with at least two of the symptoms listed in Table 4 being present $[54,55]$. Because of this requirement, the early diagnosis of faecal stasis may be missed, particularly in older patients and those with cancer, and especially if bedridden [56]. The Rome IV criteria therefore appear more suited to use in research settings than in daily clinical practice.

Not all specialists agree on the signs and symptoms of OIC specified in the Rome IV criteria (Table 4). Indeed, some consider OIC to be a feature of OIBD rather than a separate clinical entity [41, 48, 57], while others recognise the importance of using both definitions in clinical practice $[58,59]$.

The care of patients with OIC involves physicians from different specialties, such as gastroenterology, internal medicine, oncology, geriatrics, palliative care, and pain management, and a multidisciplinary approach to defining OIC is therefore desirable. An agreed and accepted definition would facilitate comparisons between studies.

On the basis of Rome IV criteria [54, 55] and on our expertise on OIC, we propose a symptom-based definition of OIC that is easy to apply in everyday clinical practice, both in community care settings (e.g. in primary care and nursing homes) and in hospitals (Table 5). To avoid the overdiagnosis of OIC, we consider a sign/symptom duration of at least 2 weeks to be reasonable. To facilitate prompt diagnosis, the BSFS should be administered at the first visit to all patients being prescribed opioids. It is important to note, however, that the symptoms of constipation are highly subjective, and based on the individual patient's judgement of stool appearance, perceived discomfort and ease of defecation [23, 48, 50, 52, 60]. We therefore advocate a careful overall assessment of all the symptoms described by patients with OIC. Moreover, given the effects of opioids on the 
Table 3 Symptoms and signs of opioid-induced bowel dysfunction

Heartburn and/or acid reflux

Postprandial epigastric distention

Epigastric pain

Sensation of slow and/or incomplete digestion

Nausea and/or vomiting

Bloating and/or flatulence

Abdominal pain

Hard stools

entire GI tract, many patients may report symptoms consistent with OIBD in addition to those typical of OIC.

\section{EPIDEMIOLOGY}

\section{General Considerations}

As a result of the minimal amount of epidemiological data available for OIBD, there is no clear and reliable picture of the prevalence and frequency of this condition [61].

The prevalence of OIC varies widely in international studies, from $8.9 \%$ to $81 \%$, mainly because of the lack of a standardised definition
[62-73]. Similar variation is also observed in Italian studies in both the oncology (including palliative care) and non-oncology settings. However, we believe that comparisons between studies would remain problematic even if a consensus was reached on classification, because of additional sources of variability in both the clinical and research settings (Table 6). We believe a possible solution may lie in conducting epidemiological studies in which variation is minimised (e.g. by restricting the study to either the cancer or non-cancer setting, or by focusing on a single disease stage, care setting or opioid).

In our experience, the prevalence of OIC is high in non-cancer settings in Italy. We estimate that, without appropriate intervention, more than $50 \%$ of patients prescribed a strong opioid develop OIC regardless of the underlying disease. We therefore consider it necessary to use preventive or therapeutic interventions in most patients receiving opioids, to eliminate or at least mitigate the potentially negative effects of OIC on adherence and, consequently, on effective pain relief.

Currently, there are no known quantitative or qualitative Italian data relating to the measurement or monitoring of GI function in patients receiving cancer treatment, palliative care or pain relief, beyond research settings $[47,74]$. We believe that the evaluation of

Table 4 Rome IV diagnostic criteria for opioid-induced constipation [54, 55]

1. New or worsening symptoms of constipation when initiating, changing or increasing opioid therapy that must include two or more of the following symptoms:

a. Straining for more than $25 \%$ of defecation attempts

b. Lumpy or hard stools (BSFS 1-2) for more than $25 \%$ of defecation attempts

c. Sensation of incomplete evacuation for more than $25 \%$ of defecation attempts

d. Sensation of anorectal obstruction or blockage for more than $25 \%$ of defecation attempts

e. Manual manoeuvres required to defecate for at least $25 \%$ of defecation attempts

f. $<3$ spontaneous bowel movements per week

2. Loose stools are rarely present without the use of laxatives

BSFS Bristol Stool Form Scale 
Table 5 Proposed definition of opioid-induced constipation based on Rome IV criteria and on panellists' expert opinion on $\mathrm{OIC}$

Appearance or worsening of one of the following signs and symptoms, persisting for at least 2 weeks, after initiating, changing or increasing opioid therapy in the absence of laxative use

a. Straining

b. Lumpy or hard stools (BSFS 1-2)

c. Sensation of incomplete bowel evacuation

d. Sensation of anorectal obstruction/blockage

e. $<3$ spontaneous bowel movements in a week

BSFS Bristol Stool Form Scale

bowel function is not standardised in most Italian healthcare settings, even in opioid-treated patients. Where bowel function is evaluated, it is limited to a general ex post assessment of bowel movements that is done weekly in patients attending outpatient clinics, twice weekly in those receiving palliative care at home, and daily in inpatient care settings. In general, monitoring of GI symptoms and bowel function tends to be done by nursing rather than medical staff in Italy, regardless of the setting.

The paucity of published data on the epidemiology of OIC in Italy stems primarily from the lack of standardisation of procedures and methods for its measurement and monitoring, beyond those used in research settings. This is despite a large number of professionals working in approximately 1300 oncology, palliative care and pain relief centres that commonly provide opioid treatment. This gap would be even greater if we took into consideration the other specialist centres that provide treatment for chronic pain (e.g. orthopaedic centres), longterm care centres, and the prescribing of opioids by primary care physicians.

However, evidence that OIC is prevalent in Italy was confirmed in a multicentre, prospective observational study of 2324 patients receiving opioid treatment [47]. The prevalence of GI symptoms (classified as opioid-induced dysfunction) was $63.5 \%$. It should be noted that, at the time of the study (2010), the only opioid antagonist approved for the treatment of
OIC was methylnaltrexone, which was very rarely used. Further indirect evidence of the importance of OIC in clinical practice can be inferred from the steep increase in the use of slow-release oxycodone/naloxone in Italy after 2010 [74]. This year marked the beginning of a transition phase, in which subcutaneously administered methylnaltrexone was no longer marketed, but peripherally acting $\mu$ receptor antagonists were not yet available. In the absence of specific treatments for OIC, there was considerable clinical uptake of the fixeddose combination of oxycodone/naloxone [74]. There were, however, limitations of this product: the fixed dose ratio (2:1), which did not allow the components to be individually dose titrated, and the obligation to use a specific opioid, oxycodone, for pain relief. With fixeddose oxycodone/naltrexone, increasing the daily opioid dose carries an inherent risk of breaching the dosage threshold for central naltrexone activity, which would blunt the desired analgesic effect.

\section{Epidemiology of OIC in Patients with Cancer}

Constipation is prevalent among patients with cancer, affecting 70-100\% of those in hospital [75]. However, it acquires specific importance and characteristics when opioids are used to control cancer-related pain; in these patients, OIC is a predictable unwanted effect.

Several Italian studies have investigated the prevalence of OIC in patients with cancer. In one study comparing 4 weeks' treatment with 
Table 6 Main factors contributing to the variability of pharmacoepidemiological data on opioid-induced constipation (OIC)

Factors related to specific study characteristics

Study type and design (e.g. retrospective vs prospective)

Setting

1. Specific:

Palliative care: hospice, home, outpatient clinic, day hospital

Pain therapy: inpatient, outpatient, day hospital

Oncology: inpatient, outpatient setting, day hospital

Gastroenterology: inpatient, outpatient setting, day hospital

2. Non-specific:

Hospital unit (e.g., orthopaedics, rheumatology, rehabilitation): inpatient, outpatient, day hospital

Nursing home/disabled care home (long-term care): inpatient

Primary care physician/primary care paediatrician: office, home

OIC as primary or secondary endpoint

Taxonomy related to the different criteria for diagnosis, classification and monitoring

Scales used for assessment and monitoring

Factors related to the type of healthcare professional and/or healthcare assistant performing the evaluation

Type of evaluating professional (specialist or primary care physician, psychologist, nurse, nursing assistant)

Type of specialist team (palliative care, pain therapy, oncology, gastroenterology)

Level of team sensitivity to a symptom or sign

Factors related to the patient and/or family or caregiver (especially important during the assessment phase)

Underlying condition and clinical stage during which the study is conducted (e.g. patient with stable or advancedstage cancer and pain; patient with persistent pain of non-cancer origin)

Baseline bowel function (e.g. presence or absence of idiopathic chronic constipation)

Diet and lifestyle habits at baseline and during opioid treatment

Age, sex, anthropometric data

Level of independence and functionality (e.g. bedridden, degree of mobility)

State of consciousness

Cognitive status and/or severity of cognitive decline

Ability to communicate

Cultural and psychological/relational/affective aspects relating to the patient (and family/caregiver) that may affect the ability to objectively establish clinical aspects essential for formulating a diagnosis (e.g. nausea, vomiting, stool features) 
Table 6 continued

Factors related to opioid therapy

Patient opioid-naive or -experienced

Strength of the opioid used (weak vs strong)

Speed and duration of action of opioid (rapid-onset, short-acting, long-acting)

Method and route of administration (parenteral, oral, transmucosal, spinal)

Concurrent pharmacological treatments (with analysis of interference at gastrointestinal level)

Factors related to OIC treatment

Previous or concurrent general treatments (e.g. enemas, micro-enemas)

Previous or concurrent treatment with laxatives (single or combined), with assessment of daily dosing and pharmacological subclass (e.g. osmotics)

Pharmacological combination of opioids, laxatives and selective opioid receptor antagonists at gastrointestinal level

morphine, fentanyl, buprenorphine or oxycodone in a total of 498 patients, the prevalence of constipation was $40 \%$ among opioid-naïve patients, and around 50\% among patients switching from weak to strong opioids. However, no difference in OIC prevalence was noted between the individual opioids [76, 77]. In another study, patients $(n=187)$ previously treated with weak opioids were randomised to receive morphine or oxycodone (both orally), and constipation was assessed on a scale from 0 to 3 [78]. The mean score at the start of the study was high (2.8 for morphine vs 2.4 for oxycodone). The percentage of patients showing significant worsening of constipation after 2 weeks of treatment (defined as an increase of at least 2 points) was $25 \%$ in the morphine group and $35 \%$ in the oxycodone group. Whereas some studies have reported a lower prevalence of constipation among patients taking fentanyl compared with other hydrophilic opioids, such as morphine $[79,80]$, a real-world study failed to confirm this $[76,77]$.

Oxycodone/naloxone is associated with a lower risk of constipation compared with oxycodone alone [81, 82]. However, as noted earlier, dosages of each component cannot be titrated independently, and there is therefore a risk that analgesic effect will decline (owing to the activity of naloxone at central $\mu$ receptors) as the dosage increases [83, 84].

Low doses of oxycodone/naloxone were evaluated in a retrospective study of 186 opioidnaïve patients aged at least 75 years with chronic pain and pre-existing constipation (mean Bowel Function Index [BFI] 64.1), most of whom $(89.2 \%)$ were taking laxative treatment. BFI improved over 60 days (mean change -28.2; $P<0.0001$ ) and laxative use decreased [85]. Despite these encouraging findings in mostly patients without cancer, the precise role of oxycodone/naloxone in the treatment of OIC is yet to be defined, especially in patients with cancer.

In advanced cancer and palliative care settings (e.g. hospices and home care), there is an increased frequency of new-onset or worsening constipation due to the presence of multiple risk factors (e.g. bed confinement, impaired mobility, and weakness) [86]. In 1998, an international hospice-based study found that laxative treatment was required in $74 \%$ and $87 \%$ of patients receiving weak and strong opioids, respectively, compared with $64 \%$ of those not receiving opioid therapy [87]. In a prospective Italian study of 246 patients with advanced cancer who were referred for hospice or home-based palliative care, $66.3 \%$ had constipation (defined as a BFI score of greater than 
28) at baseline [86]. One week after the start of palliative care, there was a significant decrease in constipation, as measured by change in BFI score. Importantly, however, patients without constipation on admission (i.e. BFI score of 28 or less) experienced an increase in BFI score over the same time period. Patients with a diagnosis of constipation at baseline exhibited greater use of laxatives compared to those without a diagnosis. Dehydration and benzodiazepine use were independently associated with constipation. It is clear that patients without a diagnosis of constipation tend to be under-recognised and undertreated compared to those with known constipation, in whom laxative treatment has likely been initiated.

\section{Epidemiology of OIC in Patients Without Cancer}

Very few studies of the prevalence of OIC and OIBD in patients without cancer have been conducted in Italy. We identified only two original papers published between 2005 and 2020 that included patients treated at Italian specialist centres $[47,74]$. The first of these was the prospective observational study by Rosti and co-workers referred to earlier [47], which included 772 patients treated with various opioids for non-cancer pain [47]. The second study, which was conducted retrospectively, included 1051 patients with non-cancer pain who received oxycodone/naloxone at a single centre [74].

In Italy, the dosages of opioids, especially of strong opioids, prescribed for patients without cancer are lower in comparison with patients with cancer [88]. A survey of 101 orthopaedic units in Italy, conducted 2 years after the introduction of Law 38/2010, revealed that weak opioids were prescribed for only $20.8 \%$ of patients with persistent musculoskeletal pain, and strong opioids for only $24.7 \%$ [89]. The most common reason for this low prescription rate was found to be specialists' fear of unwanted effects $(61.4 \%)$, with nausea and vomiting (48.5\%), constipation (27.7\%) and drowsiness/ sedation $(23.8 \%)$ being the most frequently mentioned AEs. In contrast, patient resistance to opioid treatment was identified as a barrier to prescription in only $29.7 \%$ of responses. Using prescription numbers as a proxy for opioid utilisation is problematic, however, because patients tend to take considerably less medication than prescribed in order to avoid unwanted effects (particularly GI effects) [90].

We consider that the prevalence of OIC among patients without cancer: (a) is higher than $50 \%$ in the absence of appropriate prophylaxis and therapy; (b) increases with age, particularly in patients older than 50 years; (c) decreases to some extent with the use of laxatives [47, 74, 89, 91]. In our experience, patients aged less than 50 years tend to experience greater distress due to changes in bowel function, even though they are less likely than older patients to experience OIC.

We believe that more studies are needed to confirm findings of higher prevalence rates of OIC among patients without cancer who are female [71, 72, 92, 93]; treated in certain healthcare settings $[62,67,69,71]$; treated with specific opioids, formulations or routes of administration [64, 66, 68-70, 72, 92]; or are less than 18 years of age [94-96].

Further investigation of the pharmacoepidemiology of OIC and OIBD is mandatory both in cancer-related and non-cancer-related pain. Effectiveness is a useful endpoint in this setting because it reflects both the ability of the opioid to control pain and the adherence of patients to treatment.

\section{ECONOMIC IMPACT}

The economic impact of OIC has not been formally assessed in Italy. In Sweden, a study estimated the direct and indirect costs, in 2008 euro, incurred by patients with OIC with and without cancer [97]. Patients with severe OIC (i.e. those scoring $8-10$ on a scale from 0 to 10 ) incurred monthly costs of $€ 1525$, compared with $€ 1196$, $€ 1088$ and $€ 1034$ in patients with mild (score 1-3), moderate (score 4-7) or no OIC, respectively [97]. Most of the variation between the OIC severity subgroups was due to differences in healthcare service and medication costs [97]; the latter were $€ 192, € 148$, and $€ 121$ per month in patients with severe, moderate and mild OIC, respectively [97]. 
A more recently published qualitative analysis performed in the USA found that the cost of drug therapy for OIC was a concern for both patients and clinicians [98]. Indeed, physicians tended to recommend over-the-counter products rather than prescribe medications not covered by insurance schemes [98].

Generalising published economic data to the Italian context is very complex and not always feasible, because the Italian National Health Service (NHS) is a welfare-based system that guarantees almost free access to healthcare for Italian citizens and residents. Ideally, the economic impact of OIC should be assessed from the perspective of the NHS, and in terms of the direct and indirect costs incurred by patients and/or their caregivers.

\section{CLINICAL PRESENTATION, PHYSICAL EXAMINATION AND ASSESSMENT SCALES}

\section{Clinical Assessment}

\section{Physician-Patient Relationship}

The diagnostic and therapeutic strategies used in OIC are based not only on clinical history and symptomatology but also on all of the factors that affect the physician-patient relationship. Patients with OIC are known to experience irrational thoughts and psychological distress, and suffer from practical limitations that deserve greater attention from healthcare professionals [99, 100]. A prospective multicentre study showed that the impact of OIC is often underestimated by healthcare providers, leading to complications in OIC management [101]. It is therefore fundamentally important that healthcare professionals educate and reassure patients, encouraging them to report when OIC negatively affects their quality of life [99-101].

\section{Psychosocial Aspects}

Psychosocial aspects of OIC have only been investigated in a small number of patients, within the broader context of functional GI disorders. However, it is recognised that quality of life is significantly worsened in patients with
OIC [55]. In a survey of patients taking opioids for chronic non-cancer-related pain $(n=489)$ [102], most reported significant limitations in their dietary choices, and almost half reported limitations in normal activities of daily living and sexual activity (49\% and $46 \%$, respectively). In another study, $45 \%$ of 419 patients taking chronic opioid therapy for relief of non-cancer pain reported that OIC interfered with pain management [73]. A reduction of opioid dosage in response to OIC may result in a further worsening of quality of life, owing to poorer control of chronic pain [55]. According to the findings of a survey published in 2009, onethird of the patients who were prescribed opioids either failed to start taking them or selfreduced the dose or discontinued treatment because of bothersome OIC symptoms [63].

We therefore agree that there is a need to develop multidisciplinary expertise on the prevention, early diagnosis and appropriate management of OIC, because failure to control OIC inevitably jeopardises optimal opioid use and, ultimately, the treatment of persistent pain that is not otherwise manageable.

\section{Bowel Function History}

Patient history is the mainstay of OIC prevention and early diagnosis. Whenever a bowel function disorder is reported, the first diagnostic step should be to analyse clinical documentation and/or collect data that allows the temporal relationship between the onset (or worsening) of bowel symptoms and the start of opioid treatment to be assessed [45]. When symptoms predate opioid therapy, it is important to assess how bowel function was managed, and with what results. Some patients forgo oral laxatives or rectal stimulants, resorting instead to straining, dietary modification and/or intense physical activity. Alternatively, oral laxatives and/or rectal stimulants may be used on an as-needed or regular, pre-emptive, basis. In patients who use laxatives and/or enemas on a daily basis, it is impossible to establish the presence of spontaneous bowel movements; moreover, the excessive use of stimulants normally results in production of poorly formed 
liquid stools and excessive colonic emptying [59]. Consequently, it is difficult to ascertain whether constipation was ever actually present, or whether the use of medication was an attempt to ameliorate other GI symptoms associated with opioid use, such as bloating and abdominal distension.

Despite their similar symptomatology, OIC and chronic idiopathic constipation differ in terms of their pathophysiology, patient characteristics and prognosis; thus, differentiating between these two conditions is important and must be based on well-defined clinical criteria [55]. This recommendation appears even more important in view of the fact that, according to a recent meta-analysis, most studies do not include in their definition of OIC a recent history of opioid therapy, the presence of pre-existing constipation or a change in bowel habit [52].

We recommend asking patients about bowel movement frequency and stool consistency, as well as symptoms such as straining, sensation of incomplete evacuation, manual manoeuvres to aid evacuation and faecal incontinence. The BSFS is a useful tool for evaluating the consistency and morphological appearance of stools; it has also been recognised as a reliable, noninvasive marker of colonic transit, and a means of assessing treatment outcomes in patients with constipation [103]. We believe it is useful to use the BSFS in all patients receiving opioids from the beginning of treatment, regardless of whether symptoms of OIC are reported. This approach differs from Rome IV, which recommends using the BSFS only in patients who report symptoms of constipation. Pre-emptive application of the BSFS facilitates the early diagnosis of OIC, and works with our proposed definition (Table 5) which allows a diagnosis of OIC to be established in the presence of only one symptom or sign. We recommend using the BSFS in this way because the scale closely correlates with intestinal transit time [104, 105].

A particularly important issue is the prevention and detection of 'silent' constipation. This typically occurs in patients who, because of physical and/or mental impairment, either do not recognise the symptoms of constipation or cannot communicate them to healthcare professionals or caregivers.

In these cases, there is a need for a more proactive approach to the prevention and detection of constipation, involving daily monitoring of bowel function, regular application of the BSFS and, if necessary, digital rectal examination [106].

This preventive and proactive approach is crucial for the timely implementation of measures aimed at reducing the risk of constipation and its complications (e.g. bowel obstruction and perforation, volvulus, urinary incontinence, paradoxical diarrhoea and faecal incontinence due to faecal impaction, and psychomotor agitation) [106, 107]. It is important to realise that opioid-treated patients complaining of occasional faecal incontinence may, in fact, have faecal impaction [108].

We consider accurate perineal and digital rectal examination to be advisable in all patients requiring medical assessment for suspected OIC, as this will enable exclusion of nonopioid-related causes of constipation, such as anorectal cancer or benign anal disease (e.g. anal fissures). A concomitant anorectal disorder of functional defecation should be suspected in patients who do not respond to targeted treatment for OIC [109].

When evaluating patients with suspected OIC, it is important to look for GI symptoms and signs that may indicate OIBD (Table 3) [11]. It is not clear whether a generalised bowel function disorder can influence the response to OIC treatment [7]. Another consideration is that abdominal pain is also the cardinal symptom of narcotic bowel syndrome (NBS), which is characterised by the onset and/or worsening of abdominal pain following long-term opioid treatment [110, 111]. Over time, in patients with NBS, abdominal pain tends to decrease following progressive reduction of the opioid dose or, as described in a recent case report, upon administration of buprenorphine/naloxone [110-112].

Plain abdominal radiography is appropriate for identifying anatomical abnormalities (e.g. dolichocolon or megacolon), together with the presence of faecal stasis or possible faecalomas [108], and for diagnosing bowel occlusion or 
Table 7 'Alarm' symptoms in opioid-induced constipation [113]
1. Rectal bleeding
2. Iron-deficiency anaemia
3. Weight loss
4. Family history of colon cancer
5. Fever

perforation. However, there is a dearth of data on the usefulness of imaging in patients with suspected OIC. Colonoscopy and/or abdominal imaging techniques should therefore be reserved for patients presenting with 'alarm' symptoms (Table 7) [113].

Special attention should be paid to circumstances and comorbidities that might worsen bowel function. These include prolonged physical inactivity (particularly confinement to bed), neurological disorders (e.g. Parkinson's disease, Alzheimer's disease), metabolic disorders with neurological complications (e.g. long-standing diabetes), and cancer. These should be taken into account in order to avoid unnecessary diagnostic procedures, particularly if invasive $[57,109]$.

Finally, in complex and frail patients (particularly older, bedridden individuals), and for those with a previous diagnosis of faecal impaction, we recommend using alternative pain management strategies (e.g. neuromodulation) before opioid therapy, particularly if prolonged therapy is anticipated. However, concerns about OIC do not justify the underuse or avoidance of opioids when alternative strategies have proven ineffective or cannot be used.

\section{Assessment Scales}

The selection and use of an assessment scale is essential to improve the management of OIC and to monitor treatment outcome. Several scales have been developed to assess the burden of chronic idiopathic constipation and can be used in patients OIC; these are shown in Table 8 , with a summary of their advantages and disadvantages. In general, considering the limited usefulness of some of these tools in routine clinical practice [114], we believe that it would be preferable to use questionnaires and other tests specifically devised and validated for OIC that are easy for patients and caregivers to understand and use. Such instruments should also be appropriate to the cultural context in which they are administered.

Of the available tools, the BFI is probably the most appropriate for use in OIC. The BFI has been tested and validated in patients with OIC, consists of only three simple questions, and allows bowel function to be quantified and assessed over time by trained healthcare professionals $[117,118]$. Patients are asked, on the basis of their experience during the previous 7 days, to rate three variables (ease of defecation, feeling of incomplete bowel evacuation, and personal judgement of constipation) on a scale from zero (no symptoms) to 100 (worst possible symptoms). The BFI score is the mean of the scores obtained in each of the three components (Fig. 1) [117], with values greater than 28.8 indicating the presence of pathological constipation. It is useful to show patients the BSFS chart when administering the BFI, as this can facilitate the assessment of bowel function by helping to assess changes in stool hydration (and therefore in colonic transit time). Patients with chronic and persistent pain are often familiar with visual analogue scales, as these are routinely used to assess and monitor pain and other symptoms [114]. A recent review confirmed the efficacy and reliability of the BFI as a rapid assessment tool with the potential to improve OIC management, in both clinical and research settings [119]. We recommend using the BFI alone for screening purposes and, although it is not specifically validated for OIC, using the BSFS to confirm the diagnosis.

\section{TREATMENT}

Until 2010, the treatment of OIC was limited to general interventions (e.g. lifestyle and dietary changes), treatment with rectal stimulants and/ or enemas, and the use of laxatives either alone or in combination with antiemetic and/or 
Table 8 Assessment scales for use in opioid-induced constipation (OIC)

\begin{tabular}{|c|c|c|}
\hline Scale & Advantages & Disadvantages \\
\hline \multirow{2}{*}{\multicolumn{2}{|c|}{$\begin{array}{l}\text { Patient Assessment of } \\
\text { Constipation-Symptoms } \\
(\text { PAC-SYM })^{\mathrm{a}}\end{array}$}} & Not yet validated for OIC \\
\hline & & $\begin{array}{l}\text { High number of questions } \rightarrow \text { time-consuming and } \\
\text { poor applicability in a clinical setting }\end{array}$ \\
\hline \multicolumn{3}{|l|}{$\begin{array}{l}\text { Patient Assessment of } \\
\text { Constipation-Quality of } \\
\text { Life (PAC-QoL) }\end{array}$} \\
\hline \multicolumn{3}{|c|}{ Knowles-Eccersley-Scott Symptom Score } \\
\hline \multicolumn{3}{|l|}{ Constipation Assessment Scale } \\
\hline \multirow[t]{2}{*}{ Stool Symptom Screener } & & Qualitative interviews \\
\hline & & $\begin{array}{l}\text { Not sufficiently validated for comparative or } \\
\text { sequential assessment of clinical status in patients } \\
\text { with OIC }[116]\end{array}$ \\
\hline \multirow[t]{3}{*}{ Bowel Function Diary } & Validated for OIC by the FDA & Not easy to use [114] \\
\hline & $\begin{array}{l}\text { Developed according to the } \\
\text { methodology based on PRO }\end{array}$ & $\begin{array}{l}\text { More suited to controlled clinical trials than to } \\
\text { routine clinical practice }[114]\end{array}$ \\
\hline & $\begin{array}{l}\text { Assessment of both symptoms and } \\
\text { their severity [115] }\end{array}$ & \\
\hline \multirow[t]{6}{*}{ Bowel Function Index } & Validated and tested for OIC & \\
\hline & Three simple questions & \\
\hline & Subjective assessment of OIC & \\
\hline & $\begin{array}{l}\text { Administered by a physician or } \\
\text { appropriately trained nurse/ } \\
\text { nursing assistant }\end{array}$ & \\
\hline & Uses numerical rating scales & \\
\hline & Fast, effective and reliable & \\
\hline
\end{tabular}

FDA US Food and Drug Administration, PRO patient-reported outcomes

${ }^{a}$ A version of PAC-SYM is also available for patients with chronic low back pain and OIC

prokinetic agents. The introduction of methylnaltrexone, the first peripherally acting $\mu$ opioid receptor antagonist (PAMORA), marked the beginning of a new era of innovative, targeted treatment strategies for OIC. However, methylnaltrexone was initially approved for subcutaneous use only, and uptake has been limited by concerns about complications, particularly GI perforation $[60,120,121]$.

\section{First-Line Treatment}

\section{General Principles}

Our recommendations for the initial management of patients with an indication for, or already receiving, chronic opioid therapy are 
1. During the last 7 days, how would you rate your ease of defecation on a scale from 0 to 100 , where 0 means 'no difficulty' and 100 means 'severe difficulty'?

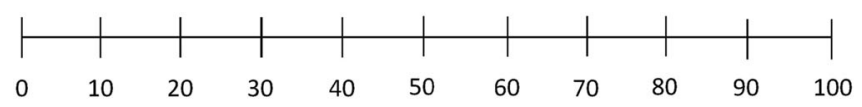

2. During the last 7 days, how would you evaluate your feeling of bowel evacuation on a scale from 0 to 100 , where 0 means 'complete' and 100 means 'incomplete'?

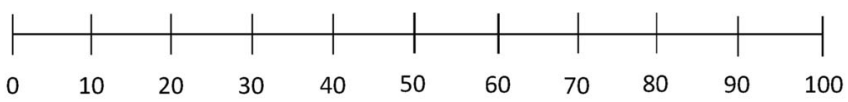

3. During the last 7 days, how would you evaluate your constipation on a scale from 0 to 100 , where 0 means 'absent' and 100 means 'severe'?

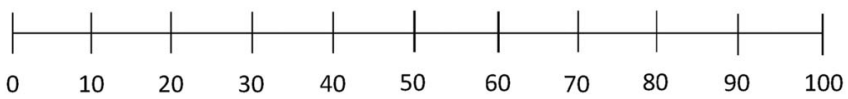

Add up the scores for Questions 1, 2, and 3, and divide the total by three.

Total score $=$ $\div 3=$ $=\mathrm{BFI}$

$\mathrm{A} \mathrm{BFI}$ value $>28.8$ indicates the presence of pathological constipation.

Fig. 1 The Bowel Function Index (BFI) [11, 117]

shown in Table 9. Before initiating opioid treatment, the patient's lifestyle, diet, concurrent therapy and bowel function (e.g. evacuation frequency, and stool shape based on the BSFS) should be evaluated [60]. Any aspects found to be inadequate or clearly pathological should be modified in a way that is tailored to the patient, their circumstances and indication for opioid therapy $[51,59,60,122]$.

The aim of increased fibre intake is to accelerate colonic transit by stimulating gut motility, since undigested fibre increases faecal volume and causes colonic distension. However, by inhibiting intestinal motility, opioids may cause an excess of fibre in the colon; this can lead to fermentation, with bloating and flatulence, and increase the risk of faecalomas [123]. The recommendation to increase dietary fibre intake in patients with OIC is justified if fibre intake is normally inadequate and if colonic transit remains normal with or without using laxatives [41, 124]. However, an increase in dietary fibre intake to at least $30 \mathrm{~g} /$ day is not always indicated because of the digestive physiology of fibre itself and the specific pathophysiology of OIC [124].

Of the many available types of dietary fibre, we recommend prescribing water-soluble agents such as psyllium (ispaghula), the use of which is supported by trials in patients with chronic functional constipation $[55,122]$. Any increase in dietary fibre should be appropriate to the patient's disease and nutritional status, and the outcome should be monitored. In patients with BSFS stool types $1-3$, we recommend prescribing laxatives to obtain stools that are easier to pass (i.e. stool types 4 and 5).

We agree with the international literature, which recommends the as-needed use of mechanical methods of stimulating evacuation reflexes, such as rectal stimulants, suppositories and micro-enemas [60]. However, care should be taken to warn patients against the inappropriate use of these agents, and to monitor their effectiveness over time.

Older patients often have multiple comorbidities. When initiating opioid treatment in this patient group, physicians should perform a careful medication review and replace, where 
Table 9 Initial management of patients with an indication for, or already receiving, chronic opioid therapy

\begin{tabular}{ll}
\hline Indication for chronic opioid therapy & $\begin{array}{l}\text { Already receiving chronic opioid therapy } \\
\text { a }\end{array}$ \\
$\begin{array}{l}\text { 1. Inform the patient that opioid use may cause or worsen } \\
\text { constipation, necessitating the use of laxatives }\end{array}$ & $\begin{array}{l}\text { 1. Administer a validated measurement scale before opioid } \\
\text { therapy (baseline) and at regular intervals (e.g. once weekly) } \\
\text { to facilitate the early detection of worsening bowel function }\end{array}$ \\
$\begin{array}{ll}\text { 2. Assess bowel function before starting opioid therapy } \\
\text { (baseline) using a validated measurement scale }\end{array}$ & $\begin{array}{l}\text { 2. If constipation is diagnosed, assess severity and possible } \\
\text { causes }\end{array}$ \\
$\begin{array}{ll}\text { 3. If bowel function is found to be abnormal, initiate } \\
\text { appropriate treatment. The aim of such treatment is to } \\
\text { avoid discontinuation of opioid treatment or a reduction } \\
\text { in dosage that could lead to recurrence of pain }\end{array}$ & $\begin{array}{l}\text { 3. Initiate laxative treatment in patients not currently } \\
\text { patients already on laxative treatment, review and, if } \\
\text { necessary, gradually intensify it. If possible, increase the dose } \\
\text { of the medication(s) already in use. If necessary, add an } \\
\text { additional agent with a complementary mechanism of }\end{array}$ \\
\end{tabular}

a With or without concomitant laxatives

possible, any medications that may adversely affect bowel motility, as well as instituting preventive OIC treatment. In addition to this, consideration should be given to the contribution of comorbidities to constipation [60, 71]. Table 10 summarises medications and comorbidities that may cause or worsen constipation in older patients. In patients living in nursing homes or other long-term care facilities, the risk of OIC can be exacerbated by immobility and decubitus ulcers, the frequent need for postoperative care, and an array of other disorders such as Parkinson's disease, diabetes, depression and dementia [62]. As a result, we believe that the decision to start OIC therapy in an older patient should be based on a multidimensional assessment carried out according to a detailed protocol.

We further recommend that patients and their families and/or caregivers should be informed of the main principles of management, or self-management, of bowel function. In particular, suggestions should be offered with respect to environmental, logistical and temporal factors that help ensure normal bowel function. These factors are often strictly related to the individual's bowel habits (e.g. having a bowel movement upon awakening each morning or after meals, in order to exploit the gastrocolic reflex) [129].

\section{Laxatives}

Laxatives are generally considered the first step in the pharmacological management of OIC, including patients with cancer [130]. It should be noted, however, that there are no specific, scientifically robust clinical trials of laxatives in the prevention and treatment of OIC in the oncology or palliative care settings. In general, laxatives should be prescribed at the lowest effective doses, and taken at set times during the day that are appropriate to the pharmacological properties of the specific preparation being used.

Osmotic laxatives such as polyethylene glycol (PEG; also known as macrogol) are the preferred agents for first-line use in OIC. PEG is inert and is neither fermented in nor absorbed from the GI tract [131-133]. Additionally, PEG has broad clinical applicability because of its favourable safety profile, and is therefore suitable for use in patients with OIC. After oral administration, PEG reaches the colon intact, where it increases stool mass via hydration $[59,60,122,133]$. It is the only laxative, besides lactulose, with proven superiority to placebo in improving symptoms of OIC in a controlled 
Table 10 Medications that may cause constipation, and comorbidities predisposing to constipation, in older patients $[71,125-128]$

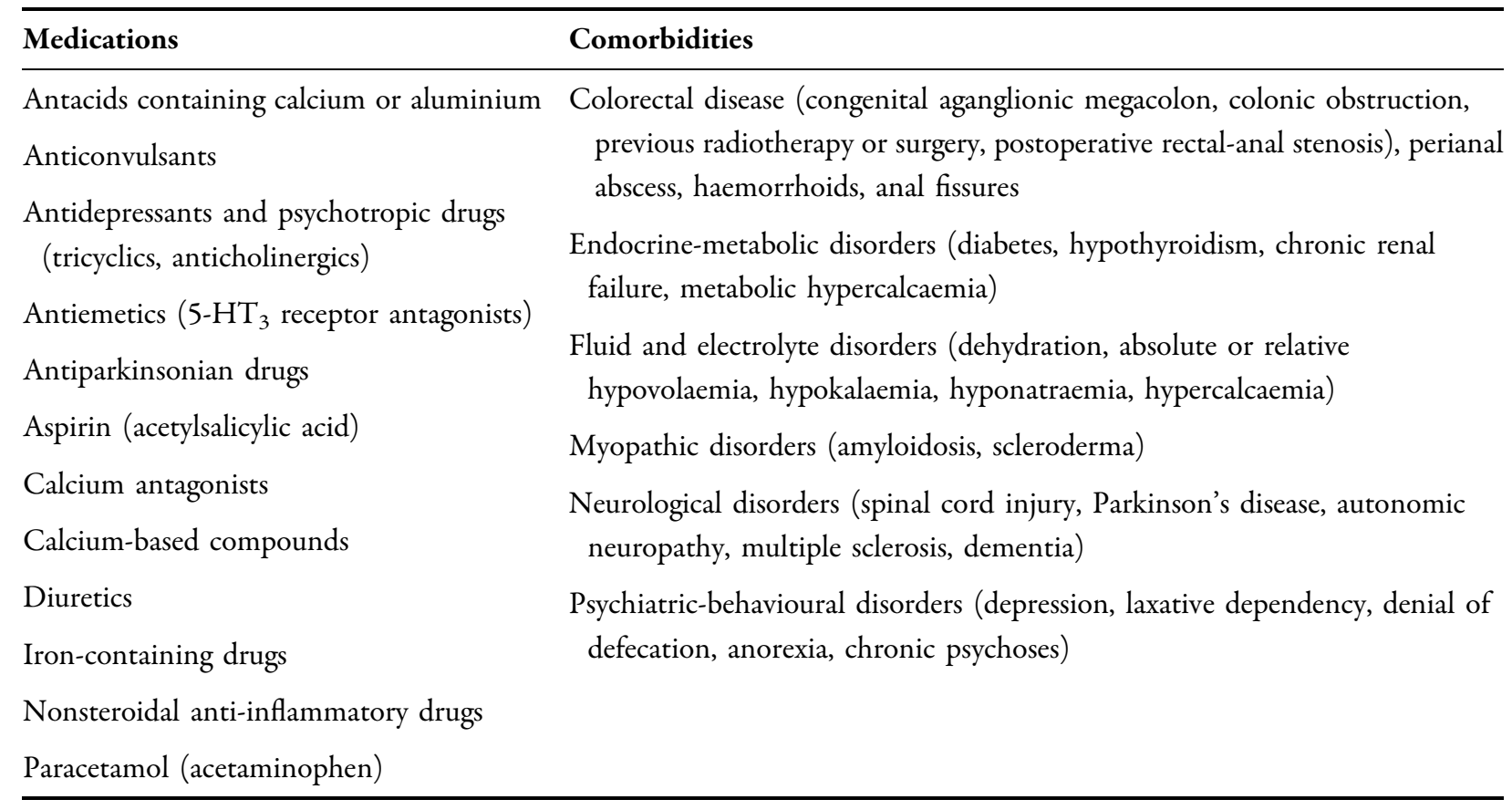

5-HT 5-hydroxytryptamine

clinical trial [134]. Unlike PEG, lactulose undergoes fermentation by gut microflora, causing bloating and flatulence, and is less suitable for use in OIC [11].

No controlled trials have been conducted to evaluate the efficacy and safety of stimulant laxatives (saline osmotic laxatives and anthraquinones) in the treatment of OIC. The clinical use of these agents in OIC is supported by extensive clinical experience and observational data, and by the extrapolation of data from controlled trials in chronic idiopathic constipation [60]. Saline osmotic laxatives should, however, be avoided in OIC because of the risk of dehydration and electrolyte disturbances, and are contraindicated in patients with renal failure [10]. Anthraquinones, such as senna, sodium picosulfate and bisacodyl, are effective in chronic idiopathic constipation, and act rapidly to improve the frequency and ease of defecation as well as stool consistency [135]. They should be administered two or three times weekly, but their efficacy tends to decline with long-term use [122]. They have no beneficial effects on abdominal pain or discomfort; in fact, they may cause abdominal pain, a recurrent urge to defecate, and faecal incontinence in patients with physical limitations or cognitive impairment.

First-line treatment should be individualised, taking into account patient preferences and circumstances $[60,122]$. Overall, the least-preferred compounds in patients with OIC are (i) insoluble fibre, because of the increased bulk and risk of faecalomas; (ii) lactulose, because of flatulence; (iii) lubricants (e.g. mineral oil), owing to their irritant and other unwanted effects; and (iv) phosphate preparations, which are contraindicated in patients with renal failure $[10,122]$. In patients with dysphagia, we recommend the use of liquid formulations (with or without a thickener) when available, or crushing tablets prior to administration. In patients fed via a nasogastric or gastrostomy tube, laxative treatment may be delivered via these routes [59].

Laxatives should preferably be taken on a regular rather than as-required basis. PEG 
should be taken once daily at an individualised dose [136], whereas stimulant laxatives should be administered two or three times weekly, on the same days each week, at the minimum effective dose [122]. In general, $75 \%$ of patients benefit from the accurate use of laxatives [122].

When response is absent or inadequate, it may be helpful to increase the dose or add a second laxative with a complementary mechanism of action (e.g. by combining an osmotic with a stimulant laxative) $[59,122]$ before concluding that laxative treatment is ineffective. In a study of 489 patients with non-cancer-related chronic pain and OIC, inadequate laxative response affected $93 \%$ of patients at baseline, and between $59 \%$ and $81 \%$ during follow-up. In patients with adequate use of at least two laxatives from different mechanistic classes, 26\% had inadequate response at baseline (11-20\% during follow-up) [137].

\section{Enemas and Other Mechanical Procedures}

The use of enemas and rectal stimulants to stimulate evacuation in patients with OIC is not supported by scientific evidence. We therefore believe that enemas, even in combination with laxatives, should be reserved for the acute treatment of faecalomas, or to prevent their development $[23,48,60]$. In our opinion, enemas should only be supplied on prescription in this setting, because they can be hazardous in patients with neutropenia, thrombocytopenia, bowel obstruction, a recent history of colorectal or gynaecological surgery, inflammatory colitis, megacolon, abdominal pain of undefined origin, diverticulosis or pelvic radiotherapy. These treatments should be prescribed with special care, and only in approved clinical indications. Their unwanted effects and complications can be life-threatening, and include haemorrhage, haematomas, abscesses, bowel wall injury, perforations and bacteraemia [60].

In the event of faecaloma of the distal sigmoid colon and rectum, manual evacuation is often unavoidable [23, 48, 60].

\section{Second-Line Treatment}

Second-line treatment of OIC involves modulating opioid treatment by combining it with a $\mu$ receptor antagonist such as a PAMORA. PAMORAs do not cross the blood-brain barrier, and thus do not block the effects of $\mu$ receptor agonists in the central nervous system. Instead, they specifically block $\mu$ receptors in the GI tract, restoring enteric nervous system function, and ameliorating the GI AEs of opioids without compromising their analgesic effects [122, 138]. In Italy, three PAMORAs are specifically approved for use in OIC: methylnaltrexone, naloxegol and naldemedine (Table 11) [139].

Several randomised, double-blind, placebocontrolled trials have investigated the efficacy and safety of methylnaltrexone both in patients with cancer-related [140-143] and non-cancerrelated [144-147] pain. In addition, meta-analyses have shown that methylnaltrexone improves bowel function (both subjectively and objectively), is well tolerated and reduces healthcare resource utilisation, but does not compromise the analgesic efficacy of concomitantly administered opioids [148, 149]. However, restrictions have been placed on the use of methylnaltrexone because of the risk of GI perforation, which has been reported in a small proportion of patients [150].

Naloxegol, the first orally administered PAMORA approved for the treatment of OIC, is a pegylated form of naloxone that does not cross the blood-brain barrier $[60,151]$ and is thus preferentially active at opioid receptors in the GI tract [151].

The efficacy and safety of naloxegol in the treatment of patients without cancer with OIC were demonstrated in two randomised, doubleblind, parallel-group, placebo-controlled, phase III trials (KODIAC-04 and KODIAC-05), conducted in a total of 1352 patients [152]. The primary endpoint of these trials was the 12-week response rate, defined as at least three spontaneous bowel movements per week and an increase from baseline of at least one spontaneous bowel movement for at least 9 of 12 weeks, and for at least 3 of the final 4 weeks, in the intention-to-treat population. Patients treated with naloxegol $25 \mathrm{mg}$ achieved 
Table 11 Dosage and administration of peripherally acting mu ( $\mu$ ) opioid receptor antagonists (PAMORAs) $[60,139,147]$

\begin{tabular}{|c|c|c|c|}
\hline Drug & $\begin{array}{l}\text { Administration } \\
\text { route }\end{array}$ & Initial dose & $\begin{array}{l}\text { Maintenance } \\
\text { dose }\end{array}$ \\
\hline \multirow[t]{6}{*}{ Methylnaltrexone } & Subcutaneous & $\begin{array}{l}\text { In adult patients with chronic pain (except palliative care patients } \\
\text { with advanced illness): }\end{array}$ & \\
\hline & & $\begin{array}{l}12 \mathrm{mg}(0.6 \mathrm{~mL}) \text { as needed, given as at least } 4 \text { doses weekly, up to } \\
\text { once daily ( } 7 \text { doses weekly) }\end{array}$ & \\
\hline & & In adult patients with advanced illness (palliative care patients): ${ }^{\mathrm{b}}$ & \\
\hline & & $8 \mathrm{mg}(0.4 \mathrm{~mL})$ for patients weighing $38-61 \mathrm{~kg}$ & \\
\hline & & $12 \mathrm{mg}(0.6 \mathrm{~mL})$ for patients weighing $62-114 \mathrm{~kg}$ & \\
\hline & Oral $^{\mathrm{c}}$ & $450 \mathrm{mg}$ & $450 \mathrm{mg} /$ day \\
\hline Naloxegol & Oral & $25 \mathrm{mg}^{\mathrm{d}}$ & $25 \mathrm{mg} /$ day $^{\mathrm{d}}$ \\
\hline Naldemedine & Oral & $0.2 \mathrm{mg} /$ day & $0.2 \mathrm{mg} /$ day \\
\hline \multicolumn{4}{|c|}{$\begin{array}{l}\text { a In these patients, treatment with usual laxatives should be stopped when commencing treatment with methylnaltrexone } \\
\text { b The usual administration schedule is one single dose every other day. Doses may also be given with longer intervals, as per } \\
\text { clinical need. Patients may receive two consecutive doses } 24 \mathrm{~h} \text { apart, only when there has been no response (bowel } \\
\text { movement) to the dose on the preceding day. Methylnaltrexone is added to usual laxative treatment } \\
\text { c Not approved for use in the European Union } \\
\text { d In patients with moderate or severe renal failure, the initial dose is } 12.5 \mathrm{mg} \text { /day. This dose can be increased to } 25 \mathrm{mg} \text { if } \\
12.5 \mathrm{mg} / \text { day is well tolerated by the patient }\end{array}$} \\
\hline
\end{tabular}

significantly higher response rates than placebo recipients $(44.4 \%$ vs $29.4 \%$, respectively, in KODIAC-04 $[P=0.001]$, and $39.7 \%$ vs $29.3 \%$, respectively, in KODIAC-05 $[P=0.02])$. Additionally, patients treated with naloxegol $12.5 \mathrm{mg}$ in the KODIAC-04 trial also had higher response rates than placebo recipients $(40.8 \%$ vs $29.4 \%$, respectively $[P=0.02])$. The median time to the first spontaneous bowel movement in patients treated with naloxegol $25 \mathrm{mg}$ was 5.9 and $12.0 \mathrm{~h}$ in the KODIAC-04 and KODIAC05 trials, respectively, compared with 35.8 and $37.2 \mathrm{~h}$ with placebo. Additionally, in both studies, the number of spontaneous bowel movements per week increased to a significantly greater extent with naloxegol treatment versus placebo. Compared with placebo, greater improvements in the severity of straining, stool consistency and the percentage of days with a complete spontaneous bowel movement were reported in both studies for patients treated with naloxegol $25 \mathrm{mg}$ and, in the KODIAK-05 trial, for naloxegol $12.5 \mathrm{mg}$. Overall, naloxegol treatment resulted in more spontaneous bowel movements per week and fewer constipationrelated symptoms versus placebo.

The safety of naloxegol was investigated in the KODIAC-08 trial [153]. Most GI AEs (mainly abdominal pain and diarrhoea) occurred early, were mild or moderate in severity and resolved during or after naloxegol discontinuation. Over 52 weeks, the use of naloxegol did not interfere with opioid analgesia or necessitate significant changes in the required opioid dose.

Although all of these trials were performed in patients with non-cancer pain, the European Medicines Agency (EMA) considered that the results were applicable to patients with cancer, including those receiving palliative care. Consequently, the EMA approved the use of naloxegol in adults with cancer and OIC who had an inadequate response to laxative treatment [60]. Recently, the first observational study of naloxegol, in 126 adult outpatients with cancer and OIC refractory to laxative treatment, has been published [154]. After 3 months, naloxegol was associated with a significant improvement in the number of spontaneous bowel 
movements (up to 5/week), and in PAC-SYM (Patient Assessment of Constipation-Symptoms) and PAC-QoL (Patient Assessment of Constipation-Quality of Life) scores.

Naldemedine is the most recently approved member of the PAMORA drug class. Naldemedine, which is structurally similar to naltrexone but does not cross the blood-brain barrier, has been investigated in phase IIb and III trials in patients with cancer and OIC [60]. In particular, two identical, randomized, phase III clinical trials (COMPOSE-1 and COMPOSE-2) evaluated the efficacy and safety of $0.2 \mathrm{mg} /$ day of naldemedine versus placebo for 12 weeks (COMPOSE1: naldemedine $n=273$, placebo $n=272$; COMPOSE-2: naldemedine $n=276$, placebo $n=274$ ) [155]. The primary endpoint of both trials was the proportion of responders (at least three spontaneous bowel movements/week and an increase of at least one spontaneous bowel movements/week from baseline for at least 9 of the 12 treatment weeks, also including at least 3 of the last 4 weeks). In both studies, a significantly larger number of responders was observed among patients who received naldemedine than placebo (COMPOSE-1: $47.6 \%$ vs $34.6 \%, \quad P=0.002 ; \quad$ COMPOSE-2: $52.5 \%$ vs $33.6 \%, P<0.0001$ ), although naldemedine was associated with a higher rate of AEs than placebo (COMPOSE-1: 22\% vs 17\%; COMPOSE-2: $20 \%$ vs $11 \%$ ), with diarrhoea and abdominal pain reported as the most frequent AEs [155].

A subsequent randomized trial, COMPOSE-3, assessed the long-term safety and efficacy of $0.2 \mathrm{mg} /$ day of naldemedine compared with placebo for 52 weeks in patients with chronic non-cancer pain (naldemedine $n=623$; placebo $n=623$ ) [156]. A similar rate of treatmentemergent AEs was reported in the two arms (68.4\% with naldemedine vs $72.1 \%$ with placebo), with a higher frequency of diarrhoea related to naldemedine $(11.0 \%$ with naldemedine vs $5.3 \%$ with placebo). No symptoms of opioid-withdrawal syndrome and decrease in opioid analgesia were observed in patients treated with naldemedine. Furthermore, a statistically significant increase in the frequency of bowel movements and improvement of quality of life were achieved with naldemedine compared with placebo [156].
In a double-blind phase III trial (COMPOSE4) and its 12-week open-label extension (COMPOSE-5), there were greater improvements from baseline in the frequency of weekly spontaneous bowel movements among patients who received naldemedine $(0.2 \mathrm{mg} /$ day orally) than in those who received placebo [157]. However, naldemedine was associated with a greater number of GI AEs than placebo, although these were mostly mild or moderate in intensity; naldemedine was therefore considered generally well tolerated $[60,157]$.

Although naldemedine and naloxegol are both PAMORAs, data from studies in animals suggest that they have distinct pharmacological profiles [158], which could translate into differences in their clinical effects. Clearly, these data require validation in human studies.

Guideline recommendations, which are based on available clinical evidence, support the use of methylnaltrexone, naloxegol and naldemedine in the management of OIC $[11,59,122]$. The Agenzia Italiana del Farmaco (AIFA), which is the national government agency that regulates prescription drug use in Italy, has recently broadened access to PAMORAs to include all patients with OIC, regardless of underlying disease or life expectancy (see Appendix 1 in the electronic supplementary material).

At present, there is no evidence to support the use of a second PAMORA in patients who do not respond adequately to a first agent in the class. We believe it would be useful to conduct clinical trials to investigate the clinical utility of PAMORA treatment in this setting but, in the meantime, such an approach cannot be recommended. Additionally, clinical trials of PAMORAs conducted to date have excluded patients with intestinal occlusion, GI lesions, or other factors that may increase the risk of GI perforation or abdominal pain $[138,140,152,153,157]$. Therefore, we recommend that patients who have pain and constipation associated with intestinal occlusion or subocclusion, or an abdominal tumour likely to affect intestinal transit, should not receive PAMORA treatment [150]. 


\section{Third-Line Treatment}

In the past decade, three drugs-prucalopride, lubiprostone and linaclotide-have been approved in the USA and Europe for the treatment of functional constipation, and constipation associated with irritable bowel syndrome. To date, none of these agents have been approved by the EMA for the treatment of OIC, although lubiprostone is approved for this use in the USA.

Prucalopride, a selective 5-hydroxytryptamine $(5-\mathrm{HT})_{4}$ receptor agonist with enterokinetic activity, was superior versus placebo in a phase II trial in patients with OIC, at least during the first week of treatment [159]. In Italy, prucalopride is indicated for the treatment of chronic constipation in adults who have not responded to laxative treatment.

Lubiprostone and linaclotide are intestinal secretagogues. Lubiprostone is a prostaglandinlike molecule that works by activating $\mathrm{ClC}-2$ chloride channels; this draws sodium ions and water into the intestinal lumen, facilitating the hydration of faecal matter and its subsequent mobilisation. Lubiprostone has been approved in the USA for the treatment of OIC, but has not yet been approved for use in this indication in the European Union. Linaclotide is a guanylate cyclase $\mathrm{C}$ agonist that has been authorized by the AIFA for the treatment of adults with moderate-to-severe constipation associated with irritable bowel syndrome. Like lubiprostone, linaclotide has not yet been granted specific authorisation in Italy for use in OIC. However, in a recent phase II clinical trial in 254 adults with chronic non-cancer pain and OIC, linaclotide had good tolerability and was associated with significantly greater improvements in OIC symptoms versus placebo [160].

In view of the fact that, in Italy and elsewhere in the European Union, prescribing of these drugs in OIC is off-label, we recommend that their use should be restricted to research settings and specialist centres. In clinical practice, we propose that these agents should be considered only after careful evaluation by highly expert, multidisciplinary teams, and that they should be reserved for use in patients with chronic non-cancer pain in whom first- and second-line treatments for OIC have proven ineffective (Fig. 2).

\section{Treatment Algorithm}

We propose an algorithm for the treatment of OIC that is based on the recommendations of current published guidelines $[7,10,11,23,41,48$,

$50,51,59,60,122,161,162]$, and on our own clinical experience (Fig. 2).

\section{FUTURE PERSPECTIVES}

Chronic and persistent pain has an enormous impact on patients' quality of life, and is frequently treated using opioid analgesics. Opioids are highly efficacious in the treatment of severe pain, and, when prescribed and monitored appropriately by trained, experienced healthcare professionals, can be used safely.

The increase in opioid prescribing throughout the Western world, including Italy, especially over the past 15 years, can be attributed to a variety of factors. The first of these is that severe pain is often associated with cancer (particularly advanced disease) and chronic non-neoplastic diseases that are often associated with aging. Thus, as the proportion of older people in a population increases, so too does the prevalence of chronic pain requiring opioid treatment. Secondly, pharmaceutical research has led to a profusion of novel opioids and formulations that have enabled analgesia to be tailored for individual patients and specific pain types. Finally, education and awareness have helped to weaken, at least in Italy, cultural associations between opioids and addiction or terminal illness; this has improved the acceptability of opioids to both physicians and patients.

With any long-term pharmacological treatment, physicians and patients must be aware of the potential for unwanted effects and should plan for their occurrence. In the case of opioids, gastrointestinal AEs such as OIC and OIBD are bothersome for patients, cause anxiety in their caregivers, and, if untreated, can impair quality of life; the result can be the discontinuation or 


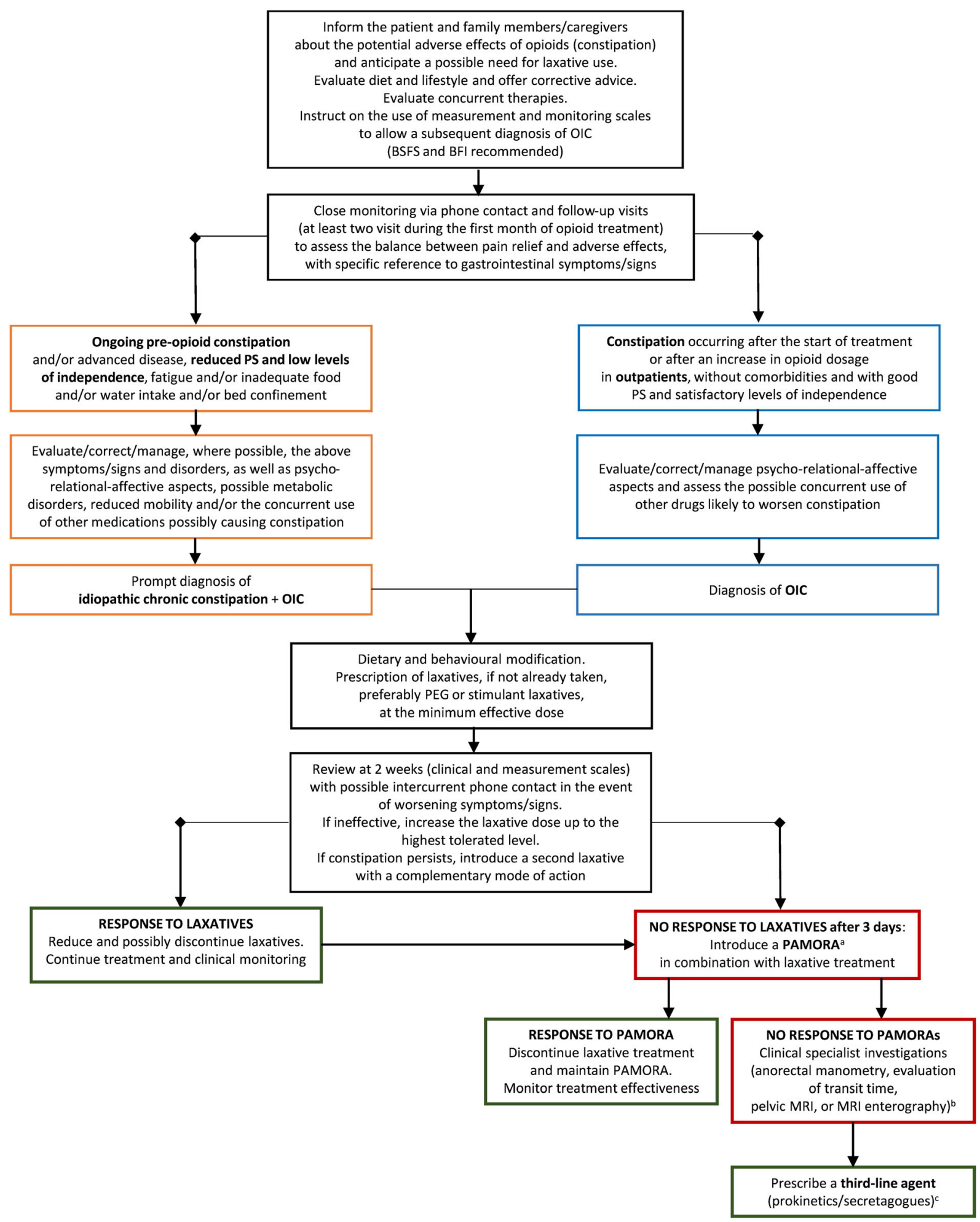

It is recommended to continuously review the case, including the diagnosis, on the basis of clinical changes 
4 Fig. 2 Algorithm for the management of opioid-induced constipation (OIC). ${ }^{\text {a }}$ PAMORAs should not be used in patients who have pain and constipation associated with intestinal occlusion or subocclusion, or abdominal tumours that may interfere with intestinal canalisation and transit time. ${ }^{\mathrm{b}}$ At the present time, there is no evidence from clinical trials to support the use of a second PAMORA in patients with non-response or an inadequate response to a first PAMORA. ${ }^{\mathrm{C}}$ Currently, the use of these agents for the treatment of OIC in Italy (and elsewhere in the European Union) is off-label, and should therefore be restricted to clinical research and specialist centres. BFI Bowel Function Index, BSFS Bristol Stool Form Scale, MRI magnetic resonance imaging, $P A M O R A$ peripherally acting $\mathrm{mu}(\mu)$ opioid receptor antagonist, $P E G$ polyethylene glycol, $P S$ performance status

interruption of otherwise effective therapy. Given that tolerance does not develop to the GI effects of opioids on the gut, it follows that an increase in opioid utilisation will be accompanied by increases in both OIC and OIBD.

In formulating our recommendations on OIC, we took into consideration recent important developments (especially pharmacological) in its prevention and treatment. Nonetheless, further multidisciplinary efforts are required to optimise the diagnosis of OIC, and to measure and monitor symptoms and signs as part of a holistic management plan.

In general, and particularly in Italy, there are still many unanswered questions, areas to be investigated and actions to be implemented in the field of OIC, including:

- Improving awareness among healthcare professionals, patients and family members/caregivers of the unwanted GI effects of opioids in order to facilitate early diagnosis

- Sharing and validating a definition of OIBD within the scientific and clinical communities; scientifically evaluating its epidemiology, most importantly with respect to its coexistence with (or independence from) OIC

- Promoting the preparation of new and the revision of existing guidelines on OIC, and ensuring their widespread dissemination to improve consistency in approaches to management; and, possibly, extending these actions to OIBD

- Alerting healthcare institutions and stakeholders to the importance of OIC, by raising awareness of (i) its impact on an already diminished quality of life for patients and their caregivers; and (ii) the economic advantage deriving from an effective OIC treatment, based on cost-effectiveness and cost-utility assessments

- Implementing OIC management strategies in more complex settings and populations, including children and adolescents; frail older people with multiple comorbidities or cognitive impairment; advanced or endstage disease; and disabling forms of chronic pain

- Increasing investment in research on OIC and OIBD, and promoting scientific interest in research areas such as

a. Evaluation of the comparative clinical GI pharmacology of opioids (to date, preclinical studies predominate), including tolerance to GI effects

b. The epidemiological impact of OIC/ OIBD in diverse specialist and care settings

c. Relationships between OIC/OIBD and variables such as age (especially in paediatric and older patients), sex and underlying disease

d. Further study of the clinical use of assessment scales, with respect to sensitivity; specificity; time needed for administration, recording and processing; and use in different populations (e.g. patients with cognitive disorders) and care settings

e. Analysis of the relationship between OIC/OIBD treatment and possible interference with the benefit-to-risk ratio of opioid treatment

f. Research that may lead to novel, more effective or better tolerated pharmacotherapeutic strategies, or that may extend the treatment algorithm

g. Research that may allow for treatment individualisation, particularly with 
regard to underlying disease (e.g. cancer or non-cancer), patient characteristics or treatment history (e.g. non-response to a first PAMORA)

h. Investigation of the clinical and pharmacological properties of PAMORA use in patients with early-stage cancer or non-cancer disease in different care settings

i. Devising and delivering training programmes for healthcare professionals and education for patients, family members and caregivers

\section{ACKNOWLEDGEMENTS}

Funding. Open access funding provided by Università degli Studi di Ferrara within the CRUI-CARE Agreement. Sponsorship for this study and the journal's Rapid Service and Open Access Fees were funded by Kyowa Kirin (Italy).

Editorial Assistance. Editorial assistance in the preparation of this article was provided by Brunilde Iovene, an independent medical writer, and Richard Crampton of Springer Healthcare. Support for this assistance was funded by Kyowa Kirin (Italy).

Authorship. The authors certify that all named authors meet the International Committee of Medical Journal Editors criteria for authorship for this article, take responsibility for the integrity of the work as a whole, and have given their approval for this version to be published.

Authors' Contributions. The authors certify that all named authors have made substantial contributions to the conception of the work; they have drafted the manuscript and revised it critically for important intellectual content; all authors gave approval of the final submitted version of the manuscript; and that they agree to be accountable for all aspects of the work in ensuring that questions related to the accuracy or integrity of any part of the work are appropriately investigated and resolved.

Disclosures. Roberto De Giorgio has received grants and honoraria for consultation from Shionogi and Takeda International; he also received honoraria from Kyowa Kyrin Italy). Giuseppe Chiarioni has received honoraria from Kyowa Kirin (Italy), Shionogi, Takeda. Sebastiano Mercadante has received a speaker honorarium from Angelini, Kyowa Kirin (Italy) and Molteni. Enrico Stefano Corazziari has received honoraria for consultation from Aboca Spa and Sofar Spa, and speaker honoraria from Kyowa Kirin (Italy). Augusto Caraceni has received personal fees from Pfizer/Eli Lilly Italia Spa, Angelini, Shionogi, Molteni, and Kyowa Kirin (Italy), and grants from Molteni \& C, Soc Esercizio Spa and Ipsen. Furio Massimino Zucco, Patrizio Odetti, Raffaele Giusti, Franco Marinangeli and Carmine Pinto declare that they have no relevant conflicts of interest.

Compliance with Ethics Guidelines. This article is based on previously conducted studies and does not contain any new studies with human participants or animals performed by any of the authors.

Open Access. This article is licensed under a Creative Commons Attribution-NonCommercial 4.0 International License, which permits any non-commercial use, sharing, adaptation, distribution and reproduction in any medium or format, as long as you give appropriate credit to the original author(s) and the source, provide a link to the Creative Commons licence, and indicate if changes were made. The images or other third party material in this article are included in the article's Creative Commons licence, unless indicated otherwise in a credit line to the material. If material is not included in the article's Creative Commons licence and your intended use is not permitted by statutory regulation or exceeds the permitted use, you will need to obtain permission directly from the copyright holder. To view a copy of this licence, visit http:// creativecommons.org/licenses/by-nc/4.0/. 


\section{REFERENCES}

1. Centers for Disease Control and Prevention, National Center for Injury Prevention and Control. U.S. opioid dispensing rate maps. https://www.cdc. gov/drugoverdose/maps/rxrate-maps.html. Accessed 30 Dec 2020.

2. Dorn S, Lembo A, Cremonini F. Opioid-induced bowel dysfunction: epidemiology, pathophysiology, diagnosis, and initial therapeutic approach. Am J Gastroenterol. 2014;2:31-7.

3. Breivik H, Collett B, Ventafridda V, et al. Survey of chronic pain in Europe: prevalence, impact on daily life, and treatment. Eur J Pain. 2006;10(4):287-333.

4. Legge 15 marzo 2010, n. 38. Disposizioni per garantire l'accesso alle cure palliative e alla terapia del dolore. (10G0056) (GU Serie Generale n. 65 del 19-03-2010). https://www.gazzettaufficiale.it/ gunewsletter/dettaglio.jsp?service $=1 \&$ datagu $=2010$ $03-19 \&$ task $=$ dettaglio\&numgu $=65 \&$ redaz $=$ 010G0056\&tmstp=1269600292070. Accessed 1 Apr 2020.

5. Bosetti C, Santucci C, Radrezza S, et al. Trends in the consumption of opioids for the treatment of severe pain in Europe, 1990-2016. Eur J Pain. 2019;23(4): 697-707.

6. Szigethy E, Knisely M, Drossman D. Opioid misuse in gastroenterology and non-opioid management of abdominal pain. Rev Nat Rev Gastroenterol Hepatol. $2018 ; 15(3): 168-80$.

7. Nelson AD, Camilleri M. Chronic opioid induced constipation in patients with nonmalignant pain: challenges and opportunities. Therap Adv Gastroenterol. 2015;8:206-20.

8. Mahler DA, Selecky PA, Harrod CG, et al. American College of Chest Physicians consensus statement on the management of dyspnea in patients with advanced lung or heart disease. Chest. 2010;137(3): 674-91.

9. Rawal H, Patel BM. Opioids in cardiovascular disease: therapeutic options. J Cardiovasc Pharmacol Ther. 2018;23(4):279-91.

10. Gruppo Italiano per la Costipazione indotta da Oppioidi. Raccomandazioni per la gestione della costipazione indotta da oppioidi. Riv Soc Itali Med Gen. 2009;2:25-32.

11. Farmer AD, Drewes AM, Chiarioni G, et al. Pathophysiology and management of opioid-induced constipation: European Expert Consensus Statement. United Eur Gastroenterol J. 2019;7(1):7-20.
12. Holzer P. Pharmacology of opioids and their effects on gastrointestinal function. Am J Gastroenterol Suppl. 2014;2:9-16.

13. Sternini C, Patierno S, Selmer IS, Kirchgessner A. The opioid system in the gastrointestinal tract. Neurogastroenterol Motil. 2004;16(Suppl 2):3-16.

14. Bagnol D, Mansour A, Akil H, Watson SJ. Cellular localisation and distribution of the cloned mu and kappa opioid receptors in rat gastrointestinal tract. Neuroscience. 1997;81(2):579-91.

15. Fickel J, Bagnol D, Watson SJ, Akil H. Opioid receptor expression in the rat gastrointestinal tract: a quantitative study with comparison to the brain. Brain Res Mol Brain Res. 1997;46(1-2):1-8.

16. Holzer P. Treatment of opioid-induced gut dysfunction. Expert Opin Investig Drugs. 2007;16(2): 181-94.

17. Galligan JJ, Sternini C. Insights into the role of opioid receptors in the GI tract: experimental evidence and therapeutic relevance. Handb Exp Pharmacol. 2017;239:363-78.

18. Kang M, Maguma HT, Smith TH, et al. The role of $\beta$ arrestin 2 in the mechanism of morphine tolerance in the mouse and guinea pig gastrointestinal tract. J Pharmacol Exp Ther. 2012;340(3):567-76.

19. Akbarali HI, Inkisar A, Dewey WL. Site and mechanism of morphine tolerance in the gastrointestinal tract. Neurogastroenterol Motil. 2014;26(10): 1361-7.

20. Galligan JJ, Akbarali HI. Molecular physiology of enteric opioid receptors. Am J Gastroenterol Suppl. 2014;2(1):17-21.

21. Wood JD, Galligan JJ. Function of opioids in the enteric nervous system. Neurogastroenterol Motil. 2004;16(Suppl 2):17-28.

22. Brock C, Olesen SS, Olesen AE, et al. Opioid-induced bowel dysfunction: pathophysiology and management. Drugs. 2012;72(14):1847-65.

23. Drewes AM, Munkholm P, Simrén M, et al. Definition, diagnosis and treatment strategies for opioidinduced bowel dysfunction-recommendations of the Nordic Working Group. Scand J Pain. 2016;11: 111-22.

24. Roy S, Liu HC, Loh HH. mu-Opioid receptorknockout mice: the role of mu-opioid receptor in gastrointestinal transit. Brain Res Mol Brain Res. 1998;56(1-2):281-3.

25. Gonenne J, Camilleri M, Ferber I, et al. Effect of alvimopan and codeine on gastrointestinal transit: 
a randomized controlled study. Clin Gastroenterol Hepatol. 2005;3(8):784-91.

26. Penagini R, Allocca M, Cantù P, et al. Relationship between motor function of the proximal stomach and transient lower oesophageal sphincter relaxation after morphine. Gut. 2004;53(9):1227-31.

27. Sun WM, Read NW, Verlinden M. Effects of loperamide oxide on gastrointestinal transit time and anorectal function in patients with chronic diarrhoea and faecal incontinence. Scand J Gastroenterol. 1997;32(1):34-8.

28. Hawkes ND, Rhodes J, Evans BK, et al. Naloxone treatment for irritable bowel syndrome-a randomized controlled trial with an oral formulation. Aliment Pharmacol Ther. 2002;16(9):1649-54.

29. Smith K, Hopp M, Mundin G, et al. Naloxone as part of a prolonged release oxycodone/naloxone combination reduces oxycodone-induced slowing of gastrointestinal transit in healthy volunteers. Expert Opin Investig Drugs. 2011;20(4):427-39.

30. Poulsen JL, Nilsson M, Brock C, et al. The impact of opioid treatment on regional gastrointestinal transit. J Neurogastroenterol Motil. 2016;22(2):282-91.

31. Nilsson M, Poulsen JL, Brock C, et al. Opioid-induced bowel dysfunction in healthy volunteers assessed with questionnaires and MRI. Eur J Gastroenterol Hepatol. 2016;28(5):514-24.

32. Huizinga JD, Chen J-H. Interstitial cells of Cajal: update on basic and clinical science. Curr Gastroenterol Rep. 2014;16(1):363.

33. Poulsen JL, Mark EB, Brock C, et al. Colorectal transit and volume during treatment with prolonged-release oxycodone/naloxone versus oxycodone plus macrogol 3350. J Neurogastroenterol Motil. 2018;24(1):119-27.

34. Olesen AE, Grønlund D, Mark EB, et al. Effects of naloxegol on gastrointestinal transit and colonic fecal volume in healthy participants receiving oxycodone. J Neurogastroenterol Motil. 2019;25(4): $602-10$.

35. Thiagarajah JR, Verkman AS. Water transport in the gastrointestinal tract. In: Johnson LR, Barrett KE, editors. Physiology of the gastrointestinal tract. 4th ed. Burlington: Elsevier; 2006.

36. Thomas J. Opioid-induced bowel dysfunction. J Pain Symptom Manag. 2008;35(1):103-13.

37. De Luca A, Coupar IM. Insight into opioid action in the intestinal tract. Pharmacol Ther. 1996;69(2): $103-15$.
38. Clarke LL, Harline MC. CFTR is required for cAMP inhibition of intestinal $\mathrm{Na}^{+}$absorption in a cystic fibrosis mouse model. Am J Physiol. 1996;270(2 Pt 1):G259-67.

39. Kunzelmann K. The cystic fibrosis transmembrane conductance regulator and its function in epithelial transport. Rev Physiol Biochem Pharmacol. 1999;137:1-70.

40. Barrett KE, Keely SJ. Chloride secretion by the intestinal epithelium: molecular basis and regulatory aspects. Annu Rev Physiol. 2000;62:535-72.

41. Müller-Lissner S, Bassotti G, Coffin B, et al. Opioidinduced constipation and bowel dysfunction: a clinical guideline. Pain Med. 2017;18(10):1837-63.

42. Kurz A, Sessler DI. Opioid-induced bowel dysfunction: pathophysiology and potential new therapies. Drugs. 2003;63(7):649-71.

43. Glad H, Ainsworth MA, Svendsen P, et al. Effect of vasoactive intestinal peptide and pituitary adenylate cyclase-activating polypeptide on pancreatic, hepatic and duodenal mucosal bicarbonate secretion in the pig. Digestion. 2003;67(1-2):56-66.

44. Pappagallo M. Incidence, prevalence, and management of opioid bowel dysfunction. Am J Surg. 2001;182(5A Suppl):11S-18S.

45. Farmer AD, Holt CB, Downes TJ, et al. Pathophysiology, diagnosis, and management of opioid-induced constipation. Lancet Gastroenterol Hepatol. 2018;3(3):203-12.

46. Panchal SJ, Muller-Schwefe P, Wurzelmann JI. Opioid-induced bowel dysfunction: prevalence, pathophysiology and burden. Int J Clin Pract. 2007;61: 1181-7.

47. Rosti G, Gatti A, Costantini A, et al. Opioid-related bowel dysfunction: prevalence and identification of predictive factors in a large sample of Italian patients on chronic treatment. Eur Rev Med Pharmacol Sci. 2010;14(12):1045-50.

48. Rossi M, Casale G, Badiali D, et al. Opioid-induced bowel dysfunction: suggestions from a multidisciplinary expert board. Support Care Cancer. 2019;27(11):4083-90.

49. Webster LR. Opioid-induced constipation. Pain Med. 2015;16(Suppl 1):S16-21.

50. Brenner DM, Stern E, Cash BD. Opioid-related constipation in patients with non-cancer pain syndromes: a review of evidence-based therapies and justification for a change in nomenclature. Curr Gastroenterol Rep. 2017;19(3):12. 
51. Lang-Illievich K, Bornemann-Cimenti H. Opioidinduced constipation: a narrative review of therapeutic options in clinical management. Korean J Pain. 2019;32(2):69-78.

52. Gaertner J, Siemens W, Camilleri M, et al. Definitions and outcome measures of clinical trials regarding opioid induced constipation: a systematic review. J Clin Gastroenterol. 2015;49(1):9-16.

53. Heaton KW, Radvan J, Cripps H, et al. Defecation frequency and timing, and stool form in the general population: a prospective study. Gut. 1992;33: 818-24.

54. Drossman DA, Hasler WL. Rome IV_functional GI disorders: disorders of gut-brain interaction. Gastroenterology. 2016;150(6):1257-61.

55. Lacy BE, Mearin F, Chang L, et al. Bowel disorders. Gastroenterology. 2016;150:1393-407.

56. Iovino P, Chiarioni G, Bilancio G, et al. New onset of constipation during long-term physical inactivity: a proof-of-concept study on the immobility-induced bowel changes. PLoS ONE. 2013;8(8):e72608.

57. Ketwaroo GA, Cheng V, Lembo A. Opioid-induced bowel dysfunction. Curr Gastroenterol Rep. 2013;15(9):344.

58. Leppert W, Zajaczkowska R, Wordliczek J. The role of oxycodone/naloxone in the management of patients with pain and opioid-induced constipation. Expert Opin Pharmacother. 2019;20(5): 511-22.

59. Hanson B, Siddique SM, Scarlett Y, Sultan S, American Gastroenterological Association Institute Clinical Guidelines Committee. American Gastroenterological Association Institute technical review on the medical management of opioid-induced constipation. Gastroenterology. 2019;156(1): 229-53.

60. Larkin PJ, Cherny NI, La Carpia D, et al. Diagnosis, assessment and management of constipation in advanced cancer: ESMO Clinical Practice Guidelines. Ann Oncol. 2018;29(Suppl 4):iv111-25.

61. Leppert W. Emerging therapies for patients with symptoms of opioid-induced bowel dysfunction. Drug Des Dev Ther. 2015;9:2215-31.

62. Allen C, Zarowitz BJ, O'Shea T, et al. Clinical and functional characteristics of nursing facility residents with opioid-induced constipation. Consult Pharm. 2017;32(5):285-98.

63. Bell TJ, Panchal SJ, Miaskowski C, et al. The prevalence, severity, and impact of opioid-induced bowel dysfunction: results of a US and European Patient Survey (PROBE 1). Pain Med. 2009;10(1):35-42.

64. Allan L, Hays $\mathrm{H}$, Jensen $\mathrm{NH}$, et al. Randomised crossover trial of transdermal fentanyl and sustained release oral morphine for treating chronic non-cancer pain. BMJ. 2001;322(7295):1154-8.

65. Kalso E, Edwards JE, Moore RA, McQuay HJ. Opioids in chronic non-cancer pain: systematic review of efficacy and safety. Pain. 2004;112(3):372-80.

66. Moore RA, McQuay HJ. Prevalence of opioid adverse events in chronic non-malignant pain: systematic review of randomised trials of oral opioids. Arthritis Res Ther. 2005;7(5):R1046-51.

67. Brown RT, Zuelsdorff M, Fleming M. Adverse effects and cognitive function among primary care patients taking opioids for chronic nonmalignant pain. J Opioid Manag. 2006;2(3):137-46.

68. Hale M, Tudor IC, Khanna S, Thipphawong J. Efficacy and tolerability of once-daily OROS hydromorphone and twice-daily extended-release oxycodone in patients with chronic, moderate to severe osteoarthritis pain: results of a 6-week, randomized, open-label, noninferiority analysis. Clin Ther. 2007;29(5):874-88.

69. Cook SF, Lanza L, Zhou X, et al. Gastrointestinal side effects in chronic opioid users: results from a population-based survey. Aliment Pharmacol Ther. 2008;27(12):1224-32.

70. Richards P, Gimbel JS, Minkowitz HS, et al. Comparison of the efficacy and safety of dual-opioid treatment with morphine plus oxycodone versus oxycodone/acetaminophen for moderate to severe acute pain after total knee arthroplasty. Clin Ther. 2013;35(4):498-511.

71. Chokhavatia S, John ES, Bridgeman MB, Dixit D. Constipation in elderly patients with noncancer pain: focus on opioid-induced constipation. Drugs Aging. 2016;33(8):557-74.

72. Ducrotté P, Milce J, Soufflet C, Fabry C. Prevalence and clinical features of opioid-induced constipation in the general population: a French study of 15,000 individuals. United Eur Gastroenterol J. 2017;5(4): 588-600.

73. Gupta A, Coyne KS, Datto C, Venuti C. The burden of opioid-induced constipation in younger patients with chronic noncancer pain. Pain Med. 2018;19(12):2459-68.

74. Gatti A, Casali M, Lazzari M, et al. Prolonged-release oxycodone/naloxone in nonmalignant pain: singlecenter study in patients with constipation. Adv Ther. 2013;30:41-59. 
75. McMillan SC. Assessing and managing opiate-induced constipation in adults with cancer. Cancer Control. 2004;11(3 Suppl):3-9.

76. Corli O, Floriani I, Roberto A, et al. Are strong opioids equally effective and safe in the treatment of chronic cancer pain? A multicenter randomized phase IV 'real life' trial on the variability of response to opioids. Ann Oncol. 2016;27(6):1107-15.

77. Corli O, Santucci C, Corsi N, et al. The burden of opioid adverse events and the influence on cancer patients' symptomatology. J Pain Symptom Manag. 2019;57(5):899-908.e6.

78. Zecca E, Brunelli C, Bracchi P, et al. Comparison of the tolerability profile of controlled-release oral morphine and oxycodone for cancer pain treatment: an open-label randomized controlled trial. J Pain Symptom Manag. 2016;52(6):783-94.e6.

79. Donner B, Zenz M, Tryba M, Strumpf M. Direct conversion from oral morphine to transdermal fentanyl: a multicenter study in patients with cancer pain. Pain. 1996;64(3):527-34.

80. Mercadante S. Diarrhea, malabsorption, constipation. In: Berger AM, Shuster JL, Von Roenn JH, editors. Principles and practice of palliative care and supportive oncology. 4th ed. Lippincott: Philadelphia; 2013. p. 175-92.

81. Luthra P, Burr NE, Brenner DM, Ford AC. Efficacy of pharmacological therapies for the treatment of opioid-induced constipation: systematic review and network meta-analysis. Gut. 2019;68:34-44.

82. Ahmedzai SH, Nauck F, Bar-Sela G, et al. A randomized, double-blind, active-controlled, doubledummy, parallel-group study to determine the safety and efficacy of oxycodone/naloxone prolonged-release tablets in patients with moderate/severe, chronic cancer pain. Palliat Med. 2012;26(1):50-60.

83. Mercadante S, Ferrera P, Adile C. High doses of oxycodone-naloxone combination may provide poor analgesia. Support Care Cancer. 2011;19(9): 1471-2.

84. Mercadante S, Giarratano A. Combined oral prolonged-release oxycodone and naloxone in chronic pain management. Expert Opin Investig Drugs. 2013;22(1):161-6.

85. Lazzari M, Marcassa C, Natoli S, et al. Switching to low-dose oral prolonged-release oxycodone/naloxone from WHO-Step I drugs in elderly patients with chronic pain at high risk of early opioid discontinuation. Clin Interv Aging. 2016;11:641-9.
86. Mercadante S, Masedu F, Maltoni M, et al. The prevalence of constipation at admission and after 1 week of palliative care: a multicenter study. Curr Med Res Opin. 2018;34(7):1187-92.

87. Sykes NP. The relationship between opioid use and laxative use in terminally ill cancer patients. Palliat Med. 1998;12(5):375-82.

88. Miceli L, Bednarova R, Di Cesare M, et al. Outpatient therapeutic chronic opioid consumption in Italy: a one-year survey. Minerva Anestesiol. 2017;83(1):33-40.

89. Fanelli G, Cherubino P, Compagnone C. Opioid use for chronic pain management in Italy: results from the Orthopedic Instant Pain Survey Project. Orthop Rev (Pavia). 2014;6(2):5309.

90. Andresen V, Banerji V, Hall G, et al. The patient burden of opioid-induced constipation: new insights from a large, multinational survey in five European countries. United Eur Gastroenterol J. 2018;6(8):1254-66.

91. De Giorgio R, Ruggeri E, Stanghellini V, et al. Chronic constipation in the elderly: a primer for the gastroenterologist. BMC Gastroenterol. 2015;15: 130.

92. Søndergaard J, Christensen HN, Ibsen R, et al. Healthcare resource use and costs of opioid-induced constipation among non-cancer and cancer patients on opioid therapy: a nationwide registerbased cohort study in Denmark. Scand J Pain. 2017;15:83-90.

93. Veiga DR, Mendonça L, Sampaio R, et al. Incidence and health related quality of life of opioid-induced constipation in chronic noncancer pain patients: a prospective multicentre cohort study. Pain Res Treat. 2018;2018:5704627.

94. Candy B, Jones L, Vickerstaff V, et al. Mu-opioid antagonists for opioid-induced bowel dysfunction in people with cancer and people receiving palliative care. Cochrane Database Syst Rev. 2018;6(6): CD006332.

95. Flogegård $H$, Ljungman G. Characteristics and adequacy of intravenous morphine infusions in children in a paediatric oncology setting. Med Pediatr Oncol. 2003;40(4):233-8.

96. Flerlage JE, Baker JN. Methylnaltrexone for opioidinduced constipation in children and adolescents and young adults with progressive incurable cancer at the end of life. J Palliat Med. 2015;18(7):631-3.

97. Hjalte F, Berggren AC, Bergendahl H, Hjortsberg C. The direct and indirect costs of opioid-induced 
constipation. J Pain Symptom Manag. 2010;40(5): 696-703.

98. Keller MS, Jusufagic A, Spiegel BMR. Patient and provider differences in the treatment of opioid-induced constipation: a qualitative study. BMC Gastroenterol. 2019;19(1):182.

99. Dhingra L, Shuk E, Grossman B, et al. A qualitative study to explore psychological distress and illness burden associated with opioid-induced constipation in cancer patients with advanced disease. Palliat Med. 2013;27(5):447-56.

100. Epstein RS, Teagarden JR, Cimen A, et al. When people with opioid-induced constipation speak: a patient survey. Adv Ther. 2017;34(3):725-31.

101. LoCasale RJ, Datto C, Wilson H, et al. The burden of opioid-induced constipation: discordance between patient and health care provider reports. J Manag Care Spec Pharm. 2016;22(3):236-45.

102. Rauck RL, Hong K-SJ, North J. Opioid-induced constipation survey in patients with chronic noncancer pain. Pain Pract. 2017;17(3):329-35.

103. Patel P, Bercik P, Morgan DG, et al. Prevalence of organic disease at colonoscopy in patients with symptoms compatible with irritable bowel syndrome: cross-sectional survey. Scand J Gastroenterol. 2015;50(7):816-23.

104. Shim L, Talley NJ, Boyce P, et al. Stool characteristics and colonic transit in irritable bowel syndrome: evaluation at two time points. Scand J Gastroenterol. 2013;48(3):295-301.

105. Jaruvongvanich V, Patcharatrakul T, Gonlachanvit S. Prediction of delayed colonic transit using Bristol stool form and stool frequency in Eastern constipated patients: a difference from the West. J Neurogastroenterol Motil. 2017;23(4):561-8.

106. International Longevity Centre (ILC) UK. The burden of constipation in our ageing population: working towards better solutions. London: ILC-UK; 2013.

107. Goodman M, Low J, Wilkinson S. Constipation management in palliative care: a survey of practices in the United Kingdom. J Pain Symptom Manag. $2005 ; 29(3): 238-44$.

108. Poitras R, Warrena D, Oyogoa S. Opioid drugs and stercoral perforation of the colon: case report and review of literature. Int J Surg Case Rep. 2018;42: 94-7.

109. Krogh K, Chiarioni G, Whitehead W. Management of chronic constipation in adults. United Eur Gastroenterol J. 2017;5(4):465-72.
110. Grunkemeier DMS, Cassara JE, Dalton CB, Drossman DA. The narcotic bowel syndrome: clinical features, pathophysiology, and management. Clin Gastroenterol Hepatol. 2007;5(10):1126-39.

111. Farmer AD, Gallagher J, Bruckner-Holt C, Aziz Q. Narcotic bowel syndrome. Lancet Gastroenterol Hepatol. 2017;2(5):361-8.

112. Loomis E, Bajwa J, Kaizuka S. Buprenorphinenaloxone as a novel treatment of narcotic bowel syndrome: a case report. Ann Intern Med. 2020;173(2):164-6.

113. Black TP, Manolakis CS, Di Palma JA. "Red flag" evaluation yield in irritable bowel syndrome. J Gastrointestin Liver Dis. 2012;21(2):153-6.

114. Dueñas M, Mendonça L, Sampaio R, et al. Reliability and validity of the Bowel Function Index for evaluating opioid-induced constipation: translation, cultural adaptation and validation of the Portuguese version (BFI-P). Curr Med Res Opin. 2017;33(3):563-72.

115. Camilleri M, Rothman M, Ho KF, Etropolski M. Validation of a bowel function diary for assessing opioid-induced constipation. Am J Gastroenterol. 2011;106(3):497-506.

116. Coyne KS, Currie BM, Holmes WC, Crawley JA. Assessment of a stool symptom screener and understanding the opioid-induced constipation symptom experience. Patient. 2015;8(4):317-27.

117. Ueberall MA, Müller-Lissner S, Buschmann-Kramm C, Bosse B. The Bowel Function Index for evaluating constipation in pain patients: definition of a reference range for a non-constipated population of pain patients. J Int Med Res. 2011;39(1):41-50.

118. Rentz AM, Yu R, Müller-Lissner S, Leyendecker P. Validation of the Bowel Function Index to detect clinically meaningful changes in opioid-induced constipation. J Med Econ. 2009;12(4):371-83.

119. Ducrotté P, Causse C. The Bowel Function Index: a new validated scale for assessing opioid-induced constipation. Curr Med Res Opin. 2012;28(3): 457-66.

120. Sizar O, Gupta M. Opioid induced constipation. Treasure Island: StatPearls; 2020.

121. Larkin PJ, Sykes NP, Centeno C, et al. The management of constipation in palliative care: clinical practice recommendations. Palliat Med. 2008;22(7): 796-807.

122. Crockett SD, Greer KB, Heidelbaugh JJ, et al. American Gastroenterological Association Institute Guideline on the medical management of opioid- 
induced constipation. Gastroenterology. 2019;156(1):218-26.

123. Mesía R, Virizuela Echaburu JA, Gómez J, et al. Opioid-induced constipation in oncological patients: new strategies of management. Curr Treat Opt Oncol. 2019;20(12):91.

124. Voderholzer WA, Schatke W, Mühldorfer BE, et al. Clinical response to dietary fiber treatment of chronic constipation. Am J Gastroenterol. 1997;92(1):95-8.

125. Chang JY, Locke GR, Schleck CD, et al. Risk factors for chronic constipation and a possible role of analgesics. Neurogastroenterol Motil. 2007;19(11): 905-11.

126. Jones RH, Tait CL. Gastrointestinal side-effects of NSAIDs in the community. Br J Clin Pract. 1995;49(2):67-70.

127. Maton PN, Burton ME. Antacids revisited: a review of their clinical pharmacology and recommended therapeutic use. Drugs. 1999;57(6):855-70.

128. Deepak P, Ehrenpreis ED. Constipation. Dis Mon. 2011;57(9):511-7.

129. Bartz S. Constipation and fecal incontinence. In: Ham R, Sloane P, Bernard M, editors. Primary care geriatrics: a case-based approach. 5th ed. Philadelphia: Mosby/Elsevier; 2006.

130. Caraceni A, Hanks G, Kaasa S, et al. Use of opioid analgesics in the treatment of cancer pain: evidence-based recommendations from the EAPC. Lancet Oncol. 2012;13(2):e58-68.

131. Corazziari E, Badiali D, Habib FI, et al. Small volume isosmotic polyethylene glycol electrolyte balanced solution (PMF-100) in treatment of chronic nonorganic constipation. Dig Dis Sci. 1996;41(8): $1636-42$.

132. De Giorgio R, Cestari R, Corinaldesi R, et al. Use of macrogol 4000 in chronic constipation. Rev Eur Rev Med Pharmacol Sci. 2011;15(8):960-6.

133. Fordtran JS, Hofmann AF. Seventy years of polyethylene glycols in gastroenterology: the journey of PEG 4000 and 3350 from nonabsorbable marker to colonoscopy preparation to osmotic laxative. Gastroenterology. 2017;152(4):675-80.

134. Freedman MD, Schwartz HJ, Roby R, Fleisher S. Tolerance and efficacy of polyethylene glycol 3350/electrolyte solution versus lactulose in relieving opiate induced constipation: a double-blinded placebo-controlled trial. J Clin Pharmacol. 1997;37(10):904-7.
135. Ford AC, Suares NC. Effect of laxatives and pharmacological therapies in chronic idiopathic constipation: systematic review and meta-analysis. Gut. 2011;60(2):209-18.

136. Corazziari E, Badiali D, Bazzocchi G, et al. Long term efficacy, safety, and tolerability of low daily doses of isosmotic polyethylene glycol electrolyte balanced solution (PMF-100) in the treatment of functional chronic constipation. Gut. 2000;46(4): $522-6$.

137. Coyne KS, Margolis MK, Yeomans K, et al. Opioidinduced constipation among patients with chronic noncancer pain in the United States, Canada, Germany, and the United Kingdom: laxative use, response, and symptom burden over time. Pain Med. 2015;16(8):1551-65.

138. Pergolizzi JV, Christo PJ, LeQuang JA, Magnusson P. The use of peripheral $\mu$-opioid receptor antagonists (PAMORA) in the management of opioid-induced constipation: an update on their efficacy and safety. Drug Des Dev Ther. 2020;14:1009-25.

139. Giusti R, Lucchesi M, Ripamonti CI. Stipsi e occlusione intestinale maligna nel paziente oncologico: valutazione dei sintomi, cause, diagnosi e trattamento. Milan: Springer Healthcare Italia; 2017.

140. Thomas J, Karver S, Cooney GA, et al. Methylnaltrexone for opioid-induced constipation in advanced illness. N Engl J Med. 2008;358(22): 2332-4.

141. Slatkin N, Thomas J, Lipman GA, et al. Methylnaltrexone for treatment of opioid-induced constipation in advanced illness patients. J Support Oncol. 2009;7(1):39-46.

142. Bull J, Wellman CV, Israel RJ, et al. Fixed-dose subcutaneous methylnaltrexone in patients with advanced illness and opioid-induced constipation: results of a randomized, placebo-controlled study and open-label extension. J Palliat Med. 2015;18(7): 593-600.

143. Chamberlain BH, Rhiner M, Slatkin NE, et al. Subcutaneous methylnaltrexone for opioid-induced constipation in advanced-illness patients with or without active cancer. Pain Manag. 2020;10(2): 73-84.

144. Iyer SS, Randazzo BP, Tzanis EL, et al. Effect of subcutaneous methylnaltrexone on patient-reported constipation symptoms. Value Health. 2011;14(1):177-83.

145. Michna E, Blonsky ER, Schulman S, et al. Subcutaneous methylnaltrexone for treatment of opioidinduced constipation in patients with chronic, 
nonmalignant pain: a randomized controlled study. J Pain. 2011;12(5):554-62.

146. Anissian L, Schwartz HW, Vincent K, et al. Subcutaneous methylnaltrexone for treatment of acute opioid-induced constipation: phase 2 study in rehabilitation after orthopedic surgery. J Hosp Med. 2012;7(2):67-72.

147. Rauck R, Slatkin NE, Stambler N, et al. Randomized, double-blind trial of oral methylnaltrexone for the treatment of opioid-induced constipation in patients with chronic noncancer pain. Pain Pract. 2017;17(6):820-8.

148. Mehta N, O'Connell K, Giambrone GP, et al. Efficacy of methylnaltrexone for the treatment of opiod-induced constipation: a meta-analysis and systematic review. Postgrad Med. 2016;128(3): 282-9.

149. Siemens W, Becker G. Methylnaltrexone for opioidinduced constipation: review and meta-analyses for objective plus subjective efficacy and safety outcomes. Ther Clin Risk Manag. 2016;12:401-12.

150. Bader S, Jaroslawski K, Blum HE, Becker G. Opioidinduced constipation in advanced illness: safety and efficacy of methylnaltrexone bromide. Clin Med Insights Oncol. 2011;5:201-11.

151. Yoon SC, Bruner HC. Naloxegol in opioid-induced constipation: a new paradigm in the treatment of a common problem. Patient Prefer Adherence. 2017;11:1265-71.

152. Chey WD, Webster L, Sostek M, et al. Naloxegol for opioid-induced constipation in patients with noncancer pain. N Engl J Med. 2014;370(25):2387-96.

153. Webster L, Chey WD, Tack J, et al. Randomised clinical trial: the long-term safety and tolerability of naloxegol in patients with pain and opioid-induced constipation. Aliment Pharmacol Ther. 2014;40(7): 771-9.

154. Dols MC, Zambrano CB, Gutiérrez LC, et al. Efficacy of naloxegol on symptoms and quality of life related to opioid-induced constipation in patients with cancer: a 3-month follow-up analysis. BMJ Support Palliat Care. 2021;11(1):25-31.

155. Hale M, Wild J, Reddy J, et al. Naldemedine versus placebo for opioid-induced constipation (COMPOSE-1 and COMPOSE-2): two multicentre, phase 3 , double-blind, randomised, parallel-group trials. Lancet Gastroenterol Hepatol. 2017;2(8):555-64.

156. Webster LR, Nalamachu S, Morlion B, et al. Longterm use of naldemedine in the treatment of opioidinduced constipation in patients with chronic noncancer pain: a randomized, double-blind, placebo-controlled phase 3 study. Pain. 2018;159(5): 987-94.

157. Katakami N, Harada T, Murata T, et al. Randomized phase III and extension studies of naldemedine in patients with opioid-induced constipation and cancer. J Clin Oncol. 2017;35(34):3859-66.

158. Kanemasa T, Koike $\mathrm{K}$, Takase $\mathrm{K}$, et al. Pharmacological profile of naldemedine, a peripherally acting $\mu$-opioid receptor antagonist: comparison with naloxone and naloxegol. J Pharmacol Exp Ther. 2020;373(3):438-44.

159. Sloots CEJ, Rykx A, Cools M, et al. Efficacy and safety of prucalopride in patients with chronic noncancer pain suffering from opioid-induced constipation. Dig Dis Sci. 2010;55:2912-21.

160. Brenner DM, Argoff CE, Fox SM, et al. Efficacy and safety of linaclotide for opioid-induced constipation in patients with chronic noncancer pain syndromes from a phase 2 randomized study. Pain. 2020;161(5):1027-36.

161. Prichard D, Norton C, Bharucha AE. Management of opioid-induced constipation. $\mathrm{Br} \mathrm{J}$ Nurs. 2016;25(10):S4-S5, S8-S11.

162. Argoff CE, Brennan MJ, Camilleri M, et al. Consensus recommendations on initiating prescription therapies for opioid-induced constipation. Pain Med. 2015;16(12):2324-37. 